\title{
Local and remote mean and extreme temperature response to regional aerosol emissions reductions
}

\author{
Daniel M. Westervelt ${ }^{1,2}$, Nora R. Mascioli ${ }^{3}$, Arlene M. Fiore ${ }^{1,4}$, Andrew J. Conley ${ }^{5}$, Jean-François Lamarque ${ }^{5}$, \\ Drew T. Shindell ${ }^{6}$, Greg Faluvegi ${ }^{2,7}$, Michael Previdi ${ }^{1}$, Gustavo Correa ${ }^{1}$, and Larry W. Horowitz ${ }^{8}$ \\ ${ }^{1}$ Lamont-Doherty Earth Observatory, Columbia University, Palisades, NY, USA \\ ${ }^{2}$ NASA Goddard Institute for Space Studies, New York, NY, USA \\ ${ }^{3}$ School of Marine Sciences, University of California San Diego, San Diego, CA, USA \\ ${ }^{4}$ Department of Earth and Environmental Sciences, Columbia University, Palisades, NY, USA \\ ${ }^{5}$ National Center for Atmospheric Research, Boulder, CO, USA \\ ${ }^{6}$ Nicholas School of the Environment, Duke University, Durham, NC, USA \\ ${ }^{7}$ Center for Climate Systems Research, Columbia University, New York, NY, USA \\ ${ }^{8}$ National Oceanic and Atmospheric Administration, Geophysical Fluid Dynamics Laboratory, Princeton, NJ, USA
}

Correspondence: Daniel M. Westervelt (danielmw@1deo.columbia.edu)

Received: 27 November 2019 - Discussion started: 9 December 2019

Revised: 4 February 2020 - Accepted: 12 February 2020 - Published: 12 March 2020

\begin{abstract}
The climatic implications of regional aerosol and precursor emissions reductions implemented to protect human health are poorly understood. We investigate the mean and extreme temperature response to regional changes in aerosol emissions using three coupled chemistry-climate models: NOAA GFDL CM3, NCAR CESM1, and NASA GISS-E2. Our approach contrasts a long present-day control simulation from each model (up to 400 years with perpetual year 2000 or 2005 emissions) with 14 individual aerosol emissions perturbation simulations (160-240 years each). We perturb emissions of sulfur dioxide $\left(\mathrm{SO}_{2}\right)$ and/or carbonaceous aerosol within six world regions and assess the statistical significance of mean and extreme temperature responses relative to internal variability determined by the control simulation and across the models. In all models, the global mean surface temperature response (perturbation minus control) to $\mathrm{SO}_{2}$ and/or carbonaceous aerosol is mostly positive (warming) and statistically significant and ranges from $+0.17 \mathrm{~K}$ (Europe $\mathrm{SO}_{2}$ ) to $-0.06 \mathrm{~K}$ (US BC). The warming response to $\mathrm{SO}_{2}$ reductions is strongest in the US and Europe perturbation simulations, both globally and regionally, with Arctic warming up to $1 \mathrm{~K}$ due to a removal of European anthropogenic $\mathrm{SO}_{2}$ emissions alone; however, even emissions from regions remote to the Arctic, such as $\mathrm{SO}_{2}$ from India, significantly warm the Arctic by up to
\end{abstract}

$0.5 \mathrm{~K}$. Arctic warming is the most robust response across each model and several aerosol emissions perturbations. The temperature response in the Northern Hemisphere midlatitudes is most sensitive to emissions perturbations within that region. In the tropics, however, the temperature response to emissions perturbations is roughly the same in magnitude as emissions perturbations either within or outside of the tropics. We find that climate sensitivity to regional aerosol perturbations ranges from 0.5 to $1.0 \mathrm{~K}\left(\mathrm{~W} \mathrm{~m}^{-2}\right)^{-1}$ depending on the region and aerosol composition and is larger than the climate sensitivity to a doubling of $\mathrm{CO}_{2}$ in two of three models. We update previous estimates of regional temperature potential (RTP), a metric for estimating the regional temperature responses to a regional emissions perturbation that can facilitate assessment of climate impacts with integrated assessment models without requiring computationally demanding coupled climate model simulations. These calculations indicate a robust regional response to aerosol forcing within the Northern Hemisphere midlatitudes, regardless of where the aerosol forcing is located longitudinally. We show that regional aerosol perturbations can significantly increase extreme temperatures on the regional scale. Except in the Arctic in the summer, extreme temperature responses largely mirror mean temperature responses to regional aerosol perturbations through a shift of the temperature distributions and are 
mostly dominated by local rather than remote aerosol forcing.

\section{Introduction}

Understanding regional climate responses to present and future anthropogenic forcing agents remains a key challenge of direct relevance to human and natural systems. Emissions of aerosols and their precursors are spatially heterogeneous and short-lived and thereby expected to exert complex responses as emissions of air pollutants are reduced through policies enacted to protect human health. Emissions of sulfur dioxide $\left(\mathrm{SO}_{2}\right)$, black carbon (BC), and organic carbon aerosol (OA) have decreased throughout the United States and Europe for several decades (Leibensperger et al., 2012; Tørseth et al., 2012). On the other hand, emissions have largely increased in recent decades in countries such as China, India, and others in the Global South; however, since 2013, emissions of $\mathrm{SO}_{2}$ have begun to decline at least in China, while emissions in India continue to increase (Fontes et al., 2017; Li et al., 2017; Lu et al., 2011; Samset et al., 2019). As emissions of anthropogenic aerosols and their precursors are reduced in high-emitting regions such as China, their reduction is expected to perturb regional and global temperatures (Kasoar et al., 2016). To improve future climate projections, a deep understanding of the magnitude, spatial pattern, statistical significance, and physical mechanisms of the temperature response to a phasing out of both scattering and absorbing anthropogenic aerosols is needed. Here we address this need by simulating the local and remote mean and extreme surface temperature responses to removal of different components of anthropogenic aerosols from six world regions in three distinct Earth system models.

The net effect of removal of global emissions of all anthropogenic aerosols is a surface warming, as decreases in aerosol scattering result in additional solar energy reaching the surface of the Earth (Myhre et al., 2013). Removal or reduction of scattering aerosols on the regional scale will also result in surface warming on average. However, removal of global and regional emissions of black carbon or other absorbing aerosol is generally expected to induce a cooling at the surface, due to a net reduction in the absorption of incoming solar radiation (Bond et al., 2013; Ramanathan and Carmichael, 2008; Samset et al., 2018). In addition to influencing surface temperature directly by scattering or absorbing incoming solar radiation (aerosol direct effect), aerosols also indirectly influence surface temperature by modulating cloud properties such as brightness and lifetime (aerosol indirect effects) (Albrecht, 1989; Twomey, 1977). Regional emissions perturbations of both scattering and absorbing aerosols also exert significant local and remote precipitation responses (Westervelt et al., 2017, 2018), though here we fo- cus primarily on mean and extreme surface temperature responses.

Several previous studies have considered the global and regional climate response to global reductions in aerosol and precursor emissions using transient future simulations (e.g., Gillett and Von Salzen, 2013; Levy et al., 2013; Samset et al., 2018; Westervelt et al., 2015), finding a robust increase of up to about $1 \mathrm{~K}$ of surface warming by 2100 in response to decreasing aerosol burden. Recently, additional studies have quantified mean surface temperature responses and radiative forcing to regional emissions changes of aerosol (Murphy, 2013). Kasoar et al. (2016) used three global climate models to estimate the global and regional surface temperature impacts from the removal of Chinese anthropogenic $\mathrm{SO}_{2}$ emissions, finding hemispheric warming in two of the three models. Conley et al. (2018) also used three climate models to estimate the mean surface temperature response to a removal of $\mathrm{SO}_{2}$ emissions from the United States alone, with warming over the United States and in the Arctic found to be as high as $0.5 \mathrm{~K}$. Persad and Caldeira (2018) used the NCAR CAM5 (Community Atmosphere Model 5) to show that climate responses to identical aerosol emissions changes are significantly different depending on the region where emissions are perturbed. Using a different model and a different emissions perturbation format, Kasoar et al. (2018) find similar patterns of mean surface temperature response to aerosols from different regions. Both Kasoar et al. (2018) and Persad and Caldeira (2018) used a single model to estimate the temperature responses to regional anthropogenic aerosol emissions.

Reductions in regional aerosol emissions may also influence temperature extremes; however, the magnitude, statistical significance, and physical mechanisms of the greenhouse gas and aerosol impact on extreme events are also poorly understood (Horton et al., 2016). The Intergovernmental Panel on Climate Change Special Report on Managing the Risks of Extreme Events and Disasters to Advance Climate Change Adaptation (IPCC SREX; IPCC, 2012) identified forcing factors that are important on regional scales (such as aerosols) as a key challenge to further understanding of the anthropogenic causes of extreme temperature change. Recent studies have found a role for global aerosol reductions in heat waves (Zhao et al., 2019) and also in temperature extreme indices (Mascioli et al., 2016; Samset et al., 2018) as defined by the Expert Team on Climate Change Detection and Indices (ETCCDI) (Sillmann et al., 2013). To our knowledge, the extreme temperature response to regional aerosol emissions reductions has not been previously studied.

In addition to understanding the changes in mean and extreme surface temperature response to aerosol reductions, it is vitally important to understand the effective radiative forcing (ERF) induced by aerosols and how ERF relates to temperature response. ERF includes the instantaneous topof-atmosphere radiative forcing plus rapid adjustments, i.e., the radiative impacts on the top-of-atmosphere energy bud- 
get which are not related to surface temperature. Radiative forcing exerted by anthropogenic aerosols is far more spatially inhomogeneous than that from well-mixed greenhouse gases, making generalization of the climate responses to anthropogenic aerosol emissions changes a more difficult task (Shindell, 2014). Additionally, radiative forcing in one region may result in different temperature response in local regions compared with remote regions. Shindell and Faluvegi (2009) began to address this by using an early version of the Goddard Institute for Space Studies ModelE chemistry-climate model to estimate temperature responses per unit of radiative forcing for forcing perturbations in several wide latitude bands. Shindell (2012) also used these latitude bands to further develop the regional temperature potential (RTP), a temperature response metric normalized by aerosol ERF to provide estimates of regional temperature change. More recently, Lewinschal et al. (2019) used NorESM (Norwegian Earth System Model) to calculate similar metrics based on emissions. Simple climate metrics such as RTP coefficients can be used in the integrated assessment modeling (IAM) and climate impact community to rapidly and easily calculate the climate impact of different energy or climate mitigation policies without requiring computationally expensive coupled climate model simulations. Thus far, metrics such as RTP incorporated into IAM have been based on simulations with a single climate model. Future climate projections can benefit and improve from a multi-model approach that enables more robust estimates of mean and extreme regional surface temperature responses per unit of radiative forcing from a given region.

The relationship between surface temperature response and associated ERF is not well understood for individual short-lived forcing agents such as regional aerosols. The climate sensitivity parameter, or the ratio between the temperature response to an external forcing and the forcing itself $\left(\mathrm{K}\left(\mathrm{W} \mathrm{m}^{-2}\right)^{-1}\right)$, is a widely used metric essential for projecting future climate change (Myhre et al., 2013; Marvel et al., 2016; Previdi et al., 2013). Estimation of equilibrium climate sensitivity (ECS) using coupled models has mostly occurred in the context of a doubling (or quadrupling) of $\mathrm{CO}_{2}$ concentrations $\left(2 \times \mathrm{CO}_{2}\right)$ (Arrhenius, 1896; Callendar, 1938; Cox et al., 2018; Huber et al., 2014; Knutti et al., 2017; Knutti and Hegerl, 2008; Knutti and Rugenstein, 2015; Otto et al., 2013). A few studies estimating the ability of single forcing agents to change surface temperature (sometimes called "forcing efficacy") have found that anthropogenic aerosols have a greater forcing efficacy than $\mathrm{CO}_{2}$ (Hansen, 2005; Marvel et al., 2016; Shindell, 2014). These findings, however, have come from single models using global reductions in aerosol and precursor emissions, despite substantial regional dependence and heterogeneity of aerosol forcing. Estimates of ECS based on modeling and modern and paleoclimatic observations should take into account the forcing efficacy of regional aerosol perturbations, which our approach can help inform.
We improve on past work by conducting an extensive set of computationally demanding simulations in three (instead of one) Coupled Model Intercomparison Project Phase 5 (CMIP5) chemistry-climate models in which emissions of $\mathrm{SO}_{2}, \mathrm{BC}, \mathrm{OA}$, and a combination of all three are set to zero or significantly reduced in one of six world regions (instead of latitude bands). Using these simulations, we estimate the local and remote regional surface temperature responses to reduced or removed aerosol and precursor emissions. We aggregate our results in each model to provide an estimate of robustness of the regional surface temperature response. In order to compare the surface temperature responses across models, regions, and forcing agents (including aerosols but also carbon dioxide) and to provide updated estimates of regional temperature response metrics as done in Shindell (2012), we estimate the climate sensitivity for a given region and forcing agent in each of our models, on a global and regional basis. We also report for the first time the extreme surface temperature response to regionally specific emissions reductions of aerosols and their precursors in three climate models.

\section{Methods}

\subsection{Models and simulations}

Our modeling framework has been previously described by Westervelt et al. (2018), Westervelt et al. (2017), and Conley et al. (2018). Briefly, we employ three coupled atmosphereocean-land-sea ice climate models with fully interactive chemistry of aerosols and trace gases: (1) Geophysical Fluid Dynamics Laboratory Coupled Climate Model version 3 (GFDL CM3) (Donner et al., 2011), (2) Goddard Institute for Space Studies ModelE2 (GISS-E2-R) (Schmidt et al., 2014), and (3) Community Earth System Model version 1 (CESM1) (Neale et al., 2012). The model configuration for each is very similar to that used for CMIP5. For further model description and model evaluation, we refer readers to Westervelt et al. (2017) and Naik et al. (2013). Only CESM1 includes prognostic simulation of aerosol size distribution (Conley et al., 2018, and references therein). Of particular relevance for our results is the model treatment of black carbon. In GFDL CM3 black carbon is internally mixed with only sulfate in the radiation code, whereas in CESM1, black carbon is internally mixed with all aerosol constituents within a given aerosol mode. In GISS-E2, black carbon is externally mixed with other aerosol species (Schmidt et al., 2014).

We conduct for each model a long "present-day" control simulation of up to 400 years in length, forced by perpetual year 2000 (2005 for NCAR CESM1) conditions, including all emissions of aerosols and their precursors and greenhouse gas concentrations. We also conduct individual regional aerosol perturbation simulations of at least 160 years and as long as 240 years in each model, in which the anthro- 
pogenic aerosol or aerosol precursor emissions for a certain region are completely removed $(100 \%)$ or reduced by the amount shown in Table 1. Aerosol emissions removals are instantaneous and we do not consider the effect of a long time-evolving drawdown. The first 20 years of the perturbation simulations are discarded in the response calculation. We choose the magnitude of relative emissions reductions in order to have roughly equivalent emissions decreases for a particular species across regions and models. As an example, "ISO2" refers to a simulation with perpetual year 2000 conditions (2005 for NCAR CESM1), perturbed by setting all anthropogenic $\mathrm{SO}_{2}$ emissions over India to zero. Other than the regional aerosol emissions perturbation, all other model settings remain identical to the control. Long control and perturbation simulations allow us to establish statistical significance and separate forced responses from internal climate variability.

We also conduct a set of simulations for each perturbation and control in each model using modeled climatological fixed sea surface temperatures (SSTs) and sea ice cover (SIC) in order to calculate ERF. These simulations only use the atmosphere and land components of the climate models and are not coupled to the ocean and sea ice models but are otherwise identical to our longer coupled model integrations. ERF is determined by differencing the perturbation simulation minus the control simulation. Estimates of ERF performed in this manner include the instantaneous radiative forcing plus the rapid adjustments from the atmosphere and the land. For the aerosol perturbation simulations, the ERF is calculated based on 50 years of simulation data for CESM1, 80 years for GFDL CM3, and 160 years for GISS-E2 (to allow detection of a smaller forcing observed in that model). The ERF associated with a doubling of $\mathrm{CO}_{2}\left(2 \times \mathrm{CO}_{2}\right)$ is also calculated using the fixed-SST method from simulations similar to $4 \times \mathrm{CO}_{2}$ fixed-SST simulations conducted for the CMIP5 experiments. For comparison, the present-day minus preindustrial aerosol ERF in CESM1, GFDL CM3, and GISS$\mathrm{E} 2$ is $-1.52,-1.60$, and $-0.76 \mathrm{Wm}^{-2}$, respectively (Allen et al., 2015). This version of the GISS-E2 model does not include the aerosol-cloud lifetime effect, resulting in a smaller ERF, as discussed below.

\subsection{Statistical methods}

We estimate the change in surface temperature between the control and perturbation simulations as the cotemporal annual mean differences (perturbation minus control), and we perform a paired sample modified Student $t$ test where the pairs are cotemporal samples of the perturbation and the control. The modified $t$ test accounts for autocorrelation in the model surface temperature time series by calculating an effective standard error, which utilizes an effective sample size based on the lag-1 autocorrelation. A time series showing autocorrelation overestimates the number of independent samples when calculating statistical significance, but our approach, based on Conley et al. (2018) and Zwiers et al. (1995), corrects against this overestimation. We also use the false discovery rate procedure of Wilks (2016) on our $t$ tests over our gridded atmospheric data, which limits the fraction of erroneously rejected null hypotheses in a field of mutually correlated $t$ tests (at each grid point).

\subsection{Extreme indices}

To estimate extreme temperature responses to aerosol perturbations, we use the "FClimDex" Fortran package (http: //etccdi.pacificclimate.org/software.shtml) developed by the Expert Team on Climate Change Detection and Indices (ETCCDI) to estimate 27 climate extreme indices. Daily minimum, maximum, and mean surface air temperature is input to the extremes package for each of our simulations for which daily data were available, including the control simulation. Cotemporal differences were then taken as for mean temperature, and we performed modified paired $t$ tests (perturbation and control) to assess significance. Extreme temperature analysis was not performed on all of our simulations but rather a subset of simulations that demonstrated the highest mean temperature response. Further, we only perform extreme analysis on simulations conducted for at least 160 years of daily data, as shorter time periods are not sufficient to build up robust statistics. We discard the first 20 years of each perturbation simulation (as with the mean surface temperature analysis) and use the corresponding matching years in the control run when creating the differences. We focus our analysis on the TXx index, one of the most commonly analyzed extreme indices in the existing literature. TXX is defined as the maximum of the maximum daily temperature in a given time period (e.g., over a modelsimulated year) (Sillmann et al., 2013). We explored results using other temperature indices and found the results to be qualitatively similar to the results for TXx, and thus we do not include these additional indices in the main text (see Supplement).

\section{Global and regional mean surface temperature responses to regional aerosol emissions}

\subsection{Comparison across models}

Figure 1 shows the $\sim 160-240$-year annual mean surface temperature response in each of the three models for six regional aerosol perturbations. An analogous figure for all of the remaining simulations can be found in Fig. S1 in the Supplement. The change in temperature in Fig. 1 and all following figures is the "perturbation minus control", representing the temperature response to a removal or reduction of emissions of anthropogenic aerosols and their precursors. Generally, the response is overwhelmingly positive (warming) with large regions of statistical significance in each of the three models for most simulations. We find a larger temper- 
Table 1. Simulation description and labels and amount of emissions perturbation (roughly the same for each model) in absolute terms and with the percentage removed.

\begin{tabular}{llll}
\hline $\begin{array}{l}\text { Simulation } \\
\text { name }\end{array}$ & $\begin{array}{l}\text { Region of emissions } \\
\text { perturbation }\end{array}$ & Species perturbed & Perturbation amount $\left(\mathrm{Tg}^{-1}\right),(\%)$ \\
\hline ESO2 & Europe & Sulfur dioxide & $18(80 \%)$ \\
EBC & Europe & Black carbon \\
EOC & Europe & Organic carbon & $0.8(100 \%)$ \\
\hline EALL & Europe & Sulfur dioxide, black carbon, organic carbon & $2(100 \%)$ \\
\hline USO2 & United States & Sulfur dioxide & $($ Sum of above $)$ \\
UBC & United States & Black carbon & $15(100 \%)$ \\
UOC & United States & Organic carbon & $0.4(100 \%)$ \\
\hline UALL & United States & Sulfur dioxide & $0.8(100 \%)$ \\
\hline CSO2 & China & Sulfur dioxide & $($ Sum of above $)$ \\
ISO2 & India & Sulfur dioxide & $15(80 \%)$ \\
IBC & India & Black carbon & $5.6(100 \%)$ \\
IOC & India & Organic carbon & $0.6(100 \%)$ \\
SABB & South America & Biomass burning sulfur dioxide, black carbon, organic carbon & $2.78(100 \%)$ \\
AFBB & Africa & Biomass burning sulfur dioxide, black carbon, organic carbon & $0.4\left(\mathrm{SO}_{2}\right), 0.4(\mathrm{BC}), 4.7(\mathrm{OA})(100 \%)$ \\
\hline
\end{tabular}

ature response in GFDL CM3 and CESM1 (first and second columns of Fig. 1) compared to GISS-E2, consistent with the smaller magnitude of aerosol ERF in GISS-E2 (see Sect. 5) resulting from a lack of a cloud lifetime effect in that model (Westervelt et al., 2017, 2018). In all three models, the largest remote temperature responses are over the Arctic, owing to the well-established polar amplification phenomenon (Smith et al., 2019; Stjern et al., 2019). Surface temperature response is strongest in the US $\mathrm{SO}_{2}$ and Europe $\mathrm{SO}_{2}$ simulations in all three models, with annual mean local and remote temperature increases of up to $1 \mathrm{~K}$ or higher. Despite different regions of emissions perturbations, the salient features of the spatial distribution of surface temperature response are similar between the US $\mathrm{SO}_{2}$, China $\mathrm{SO}_{2}$, US ALL $\left(\mathrm{SO}_{2}, \mathrm{BC}\right.$, and organic carbon aerosol (OA) combined), Europe $\mathrm{SO}_{2}$, and EU ALL (Fig. S1 in the Supplement) perturbations in all models, suggesting that aerosol forcing in Northern Hemisphere midlatitudes (NHMLs) induces a qualitatively consistent spatial response pattern. This pattern features strong Arctic warming, differential heating of the Northern Hemisphere compared to the Southern Hemisphere, strong local responses, and far-reaching remote responses across continents (e.g., European warming in response to $\mathrm{US} \mathrm{SO}_{2}$ emissions reductions). The response pattern is also similar to regional modifications of land surface albedo as reported in Seneviratne et al. (2018). Climate responses to aerosol perturbations can also project onto known modes of climate variability, such as El Niño-Southern Oscillation (ENSO), as described in Westervelt et al. (2018). The temperature response to US $\mathrm{SO}_{2}$ emissions removal in CESM1 (Fig. 1b) resembles an El Niño-like response, with cooling in the western tropical Pacific Ocean coupled with warming in the eastern tropical Pacific Ocean. In GFDL CM3, most simula- tions regardless of region or aerosol species result in cooling (sometimes statistically significant) south of $60^{\circ} \mathrm{S}$ along the Antarctic coast starting roughly at the $180^{\circ}$ meridian coupled with surrounding statistically significant warming (e.g., EU $\mathrm{SO}_{2}$, Fig. 1d), suggesting interaction with the Amundsen Sea Low (ASL), which exerts significant influence on Antarctic climate (Raphael et al., 2016). However, this is also a region of strong climate variability in GFDL CM3.

Although the surface temperature response to Indian $\mathrm{SO}_{2}$ and $\mathrm{BC}$ emissions reductions is small in all models, despite the tropical location of the emissions perturbation, changes in temperature still occur at both poles in all models, with some statistical significance. Removal of black carbon emissions (Fig. 1p, q, and r) elicits a very different temperature response in each of the three models in spatial distribution, sign, and magnitude, indicating a strong dependence of the surface temperature response on different model assumptions for black carbon, including different mixing state assumptions. Additionally, as reported in Westervelt et al. (2018), aerosol ERF from India BC perturbations is small (ranging from -0.04 to $0.06 \mathrm{~W} \mathrm{~m}^{-2}$ across the three models) and statistically insignificant, resulting in climate responses that may be influenced by internal variability. The weak forcing in the black carbon simulations may also reflect the role of rapid adjustments (Stjern et al., 2017; Smith et al., 2018), including the semi-direct effect of BC on clouds (Allen et al., 2019). The climate response to $\mathrm{BC}$ perturbations in other regions, such as US BC (Fig. S1g and h in the Supplement), is also marked by disparate temperature responses, further highlighting the sensitivity of climate response to model physics, and in some cases representing noise when forcing signals are small. The role of transport of $\mathrm{BC}$ from source 
(a) $\triangle \mathrm{T}$ GFDL US SO

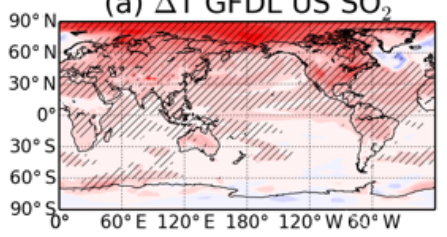

(d) $\triangle \mathrm{T}$ GFDL EU SO

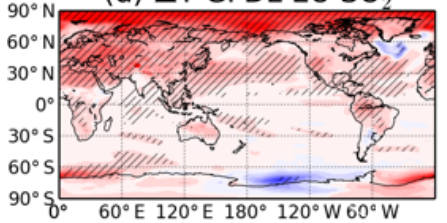

(g) $\triangle \mathrm{T}$ GFDL Ch $\mathrm{SO}_{2}$

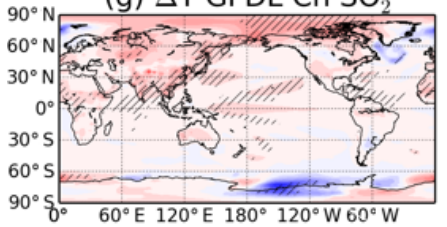

(j) $\triangle \mathrm{T}$ GFDL In $\mathrm{SO}_{2}$

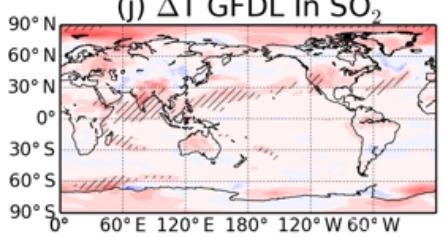

(m) $\triangle \mathrm{T}$ GFDL US ALL

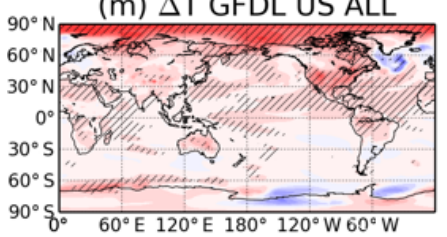

(p) $\triangle T$ GFDL In BC

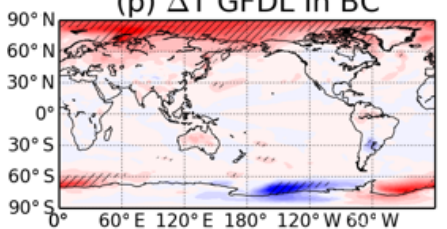

(b) $\triangle \mathrm{T}$ NCAR US SO,

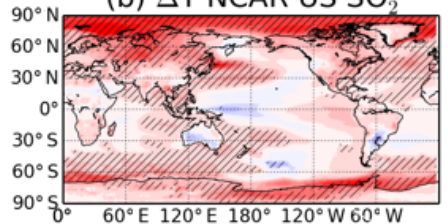

(e) $\triangle \mathrm{T}$ NCAR EU SO

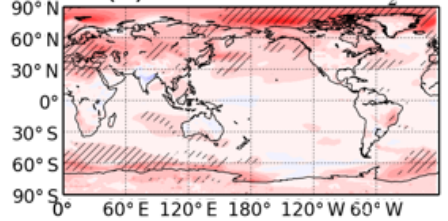

(h) $\triangle \mathrm{T}$ NCAR Ch $\mathrm{SO}_{2}$

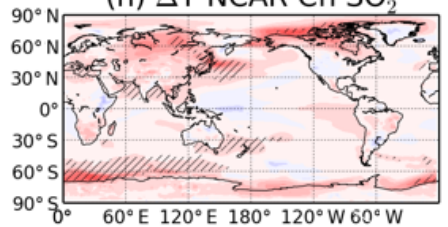

(k) $\triangle \mathrm{T}$ NCAR In $\mathrm{SO}_{2}$

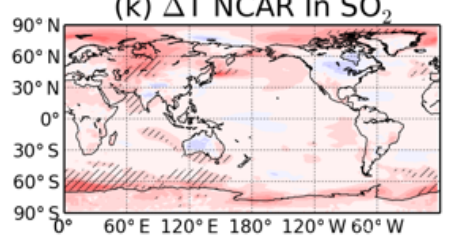

(n) $\triangle T$ NCAR US ALL

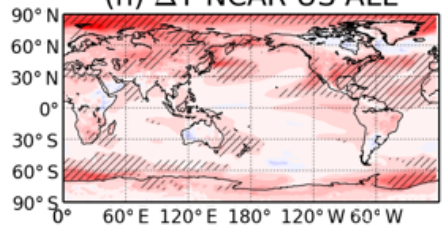

(q) $\triangle \mathrm{T}$ NCAR In BC

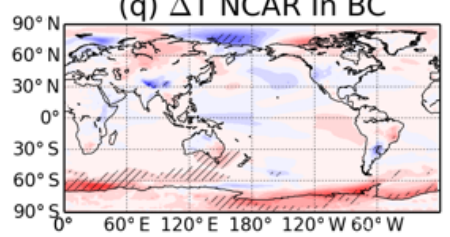

(c) $\Delta \mathrm{T}$ GISS US SO,

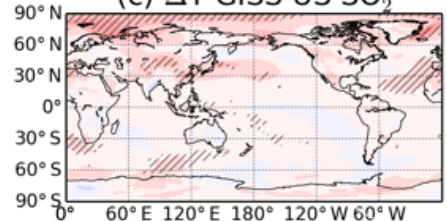

(f) $\Delta \mathrm{T}$ GISS EU SO

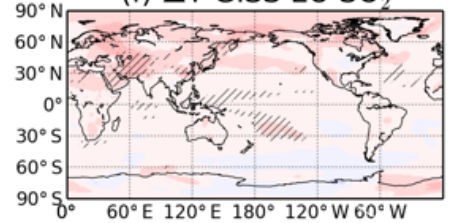

(i) $\Delta \mathrm{T}$ GISS Ch SO

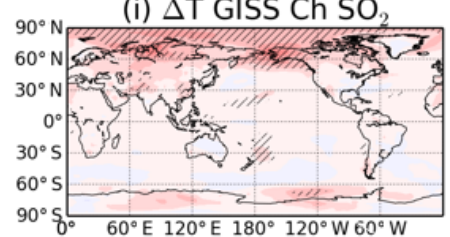

(I) $\Delta \mathrm{T}$ GISS In $\mathrm{SO}_{2}$

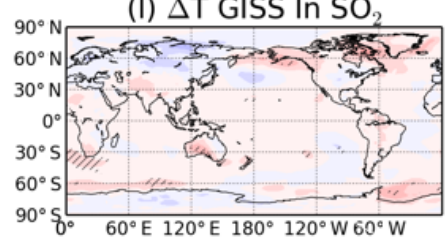

(o) $\Delta T$ GISS US ALL

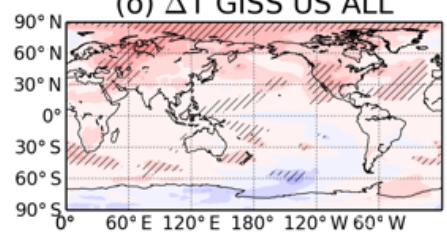

(r) $\Delta \mathrm{T}$ GISS In BC

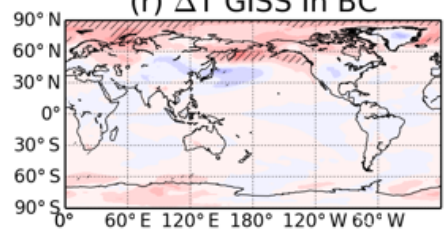

0.9

0.6

0.3

$0.0 ×$

$-0.3$

$-0.6$

Figure 1. The 200-year annual mean temperature response (K) to aerosol emissions decrease in each of the three models (GFDL CM3, first column; NCAR CESM1, second column; GISS-E2, third column) for several different regional emissions decreases (simulations indicated in figure titles; see Table 1). Hatching represents statistical significance at the $95 \%$ level according to a Student $t$ test with the false discovery rate method from Wilks (2016) applied.

regions remote to the Arctic may also be a contributor to the Arctic temperature response (Wang et al., 2014).

\subsection{Robustness across models}

To estimate robustness of the surface temperature responses to regional aerosol perturbations, we use the sign (warming or cooling) and the statistical significance as a point of comparison between the three models. Figure 2 shows the agreement between models in sign and statistical significance in each of the aerosol perturbation simulations that were conducted by all three models. We find widespread agreement in sign and significance in the US $\mathrm{SO}_{2}$ (Fig. 2a), Europe $\mathrm{SO}_{2}$ 
(Fig. 2b), China $\mathrm{SO}_{2}$ (Fig. 2c), and US ALL ( $\mathrm{SO}_{2}, \mathrm{BC}$, and OA combined, Fig. 2d) simulations. Using sign agreement in three models as a minimum for a qualification of robustness (light blue), the most robust responses are to Europe $\mathrm{SO}_{2}$ removal, where $81 \%$ of the Earth's surface qualifies as robust (values in the upper right of Fig. 2 panels). On the other hand, the response to India BC is robust across only $39 \%$ of the Earth's surface. We conclude that climate responses to black carbon over India exhibit large variability between models compared to climate responses from source regions such as the US and Europe, likely due to the small forcing exerted by the $\mathrm{BC}$ perturbation simulations.

The three models frequently agree in the sign and significance of Arctic warming, indicating that the Arctic surface temperature response is one of the most robust features of climate response to regional aerosol perturbations. Local responses are also robust; in particular the US $\mathrm{SO}_{2}$ and US ALL perturbations show high levels of robustness (green and dark blue in Fig. 2a and d) over North America. The models agree in sign and significance in the remote Arctic temperature response even in the case of the India $\mathrm{BC}$ and African biomass burning emissions perturbations, suggesting that the Arctic warming response is somewhat independent of emissions region or aerosol composition. Overall, all three models agree on sign and at least two report statistical significance over $32 \%$ of the Earth's surface $(66 \%$ when not including significance) in response to removal of $\mathrm{US} \mathrm{SO}_{2}$ emissions.

\subsection{Local and remote responses by region}

In Fig. 3, we present the global and regional mean surface temperature response to 14 different emissions perturbations in each of the three models. The emissions reductions forcing these temperature changes are roughly the same across models within a given perturbation scenario (Table 1). The global mean surface temperature response (Fig. 3a) indicates warming in 33 of the 34 simulations (US BC in GFDL CM3 being the only example of global cooling) and is significant at the $95 \%$ confidence level in 30 of the 34 perturbation simulations. The Europe and US emissions perturbations (e.g., ESO2, EALL, USO2) cause the largest global mean temperature increases across all regions and aerosol compositions, resulting in a global mean warming of about $0.15 \mathrm{~K}$. The $\mathrm{SO}_{2}$ perturbations tend to result in greater warming than $\mathrm{OA}$ or $\mathrm{BC}$ (which can also result in global cooling). CESM1 and GFDL CM3 tend to warm more than GISS-E2, although not for all simulations.

We break down the regional climate response into latitude bands, following the approach used by Shindell and Faluvegi (2009), by regionally averaging the temperature responses from 60 to $90^{\circ} \mathrm{N}$ (Arctic, Fig. 3b), 30 to $60^{\circ} \mathrm{N}$ (Northern Hemisphere midlatitudes, NHMLs, Fig. 3c), $30^{\circ} \mathrm{S}$ to $30^{\circ} \mathrm{N}$ (tropics, Fig. 3d), and 30 to $90^{\circ} \mathrm{S}$ (Southern Hemisphere, Fig. 3e). Surface temperature increases approach $1 \mathrm{~K}$ regionally averaged over the Arctic (60 to $90^{\circ} \mathrm{N}$ ) in CESM1 and
GFDL CM3, with GISS-E2 simulating smaller but still often statistically significant warming responses. The Arctic responds most strongly to European aerosol perturbations (e.g., ESO2, EALL), perhaps owing to the greater proximity of the European continent to the Arctic region. However, even remote regional aerosol perturbations, such as India $\mathrm{SO}_{2}$ (ISO2) or South American biomass burning (SABB), lead to Arctic warming in all of the models (Fig. 2), with some statistical significance. NHML temperature changes (Fig. 3c) are mostly dominated by these local perturbations. On the other hand, the temperature response to the emissions perturbations local to the tropics (red labels in Fig. 3d) is roughly the same in magnitude and significance as the response to some of the "remote" perturbations. Emissions perturbations local to the tropics exert a larger temperature response in the Arctic than they do either locally or in the closer NHML region. In the Southern Hemisphere (Fig. 3e), we find consistent, statistically significant warming in CESM1 but less warming in GFDL CM3 and GISS-E2, owing to the localized Antarctic cooling in the case of GFDL CM3. Overall, responses in the Southern Hemisphere are less statistically significant.

\section{Extreme surface temperature responses to regional aerosol emissions}

The response of temperature extremes (TXx, annual maximum of maximum daily temperature) averaged over the entire 160-240 simulation years is shown in Fig. 4 for each simulation in each model for which daily data were available. In addition to the TXx extreme index, we have also analyzed a series of other indices, however the results are qualitatively similar so we only present TXx here (see Supplement for additional indices). In general, we find increases in extreme temperature nearly everywhere both locally and remotely in most simulations, with a few exceptions such as the $\mathrm{BC}$ aerosol perturbations. Increases in extreme temperature are as large as $1 \mathrm{~K}$, especially near the source region of the particular perturbation simulation. Remote increases in extreme temperature are observed for several perturbations, for example European $\mathrm{SO}_{2}$ in NCAR CESM1 and GFDL CM3. Statistical significance is less abundant in GISS-E2, though we find increases of similar magnitude in GISS-E2 and the other two models. Over land, extreme temperature (TXx) can be equally or more sensitive to regional aerosol forcing than mean temperature, which can be seen by comparing temperature changes in Figs. 1 and 4. For example, TXx response to US $\mathrm{SO}_{2}$ is mostly similar in magnitude or slightly larger than mean temperature over the eastern US in all three models. In contrast, mean temperature changes are strong (up to $1 \mathrm{~K}$ ) over the Arctic, whereas extreme temperature changes (TXx) are much smaller $(<0.3 \mathrm{~K})$ and statistically insignificant. This is likely caused by the seasonality of Arctic amplification, which is a robust response to external forcing in every season except summer. TXx values 

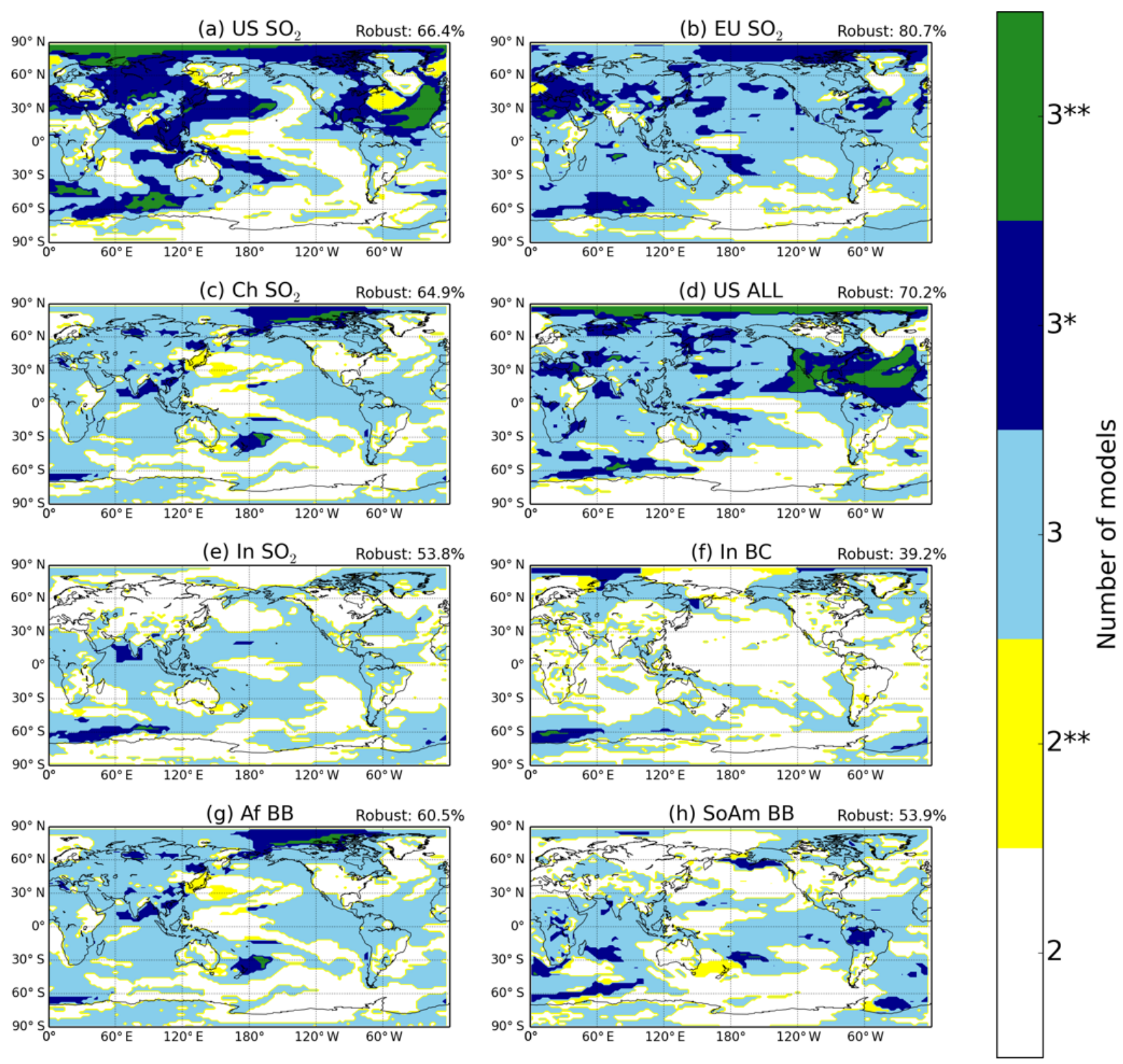

Figure 2. Regions of robustness in surface temperature response to individual aerosol emissions perturbations (a-h). The different colors represent the number of models in agreement in sign (two or three) for a particular location, and asterisks indicate whether models agree that the response is statistically significant ${ }^{* *}$ for significance in all three or both models, ${ }^{*}$ for significance in two out of three models, and no asterisks for significance in one or no models). Robustness indicates percentage of the surface area that has all three models in sign agreement.

mostly reflect summer temperature changes, when the maximum temperature throughout the year is likely to occur in the Northern Hemisphere. We confirm this by showing extreme temperature response for the winter months December, January, and February (DJF, Fig. S2), in which Arctic extreme temperature responses are larger and consistent with mean temperature responses. We conclude that the remote response relationship between mean and extreme temperatures is therefore strongly seasonally dependent.
Figure 5 shows the global (a) and latitude band averaged (b-e) extreme surface temperature response in each of the model simulations, analogous to Fig. 3 for mean surface temperatures. Another extreme temperature metric TX90p, or the percentage of days when the daily maximum temperature is greater than the 90th percentile, is shown in Fig. S3 but is qualitatively similar to Fig. 5. Global mean extreme surface temperature response is largest in GFDL CM3 and CESM1 and in the Europe $\mathrm{SO}_{2}$ (ESO2) and $\mathrm{US} \mathrm{SO}_{2}$ (USO2) simulations, in which the TXx response can approach about 

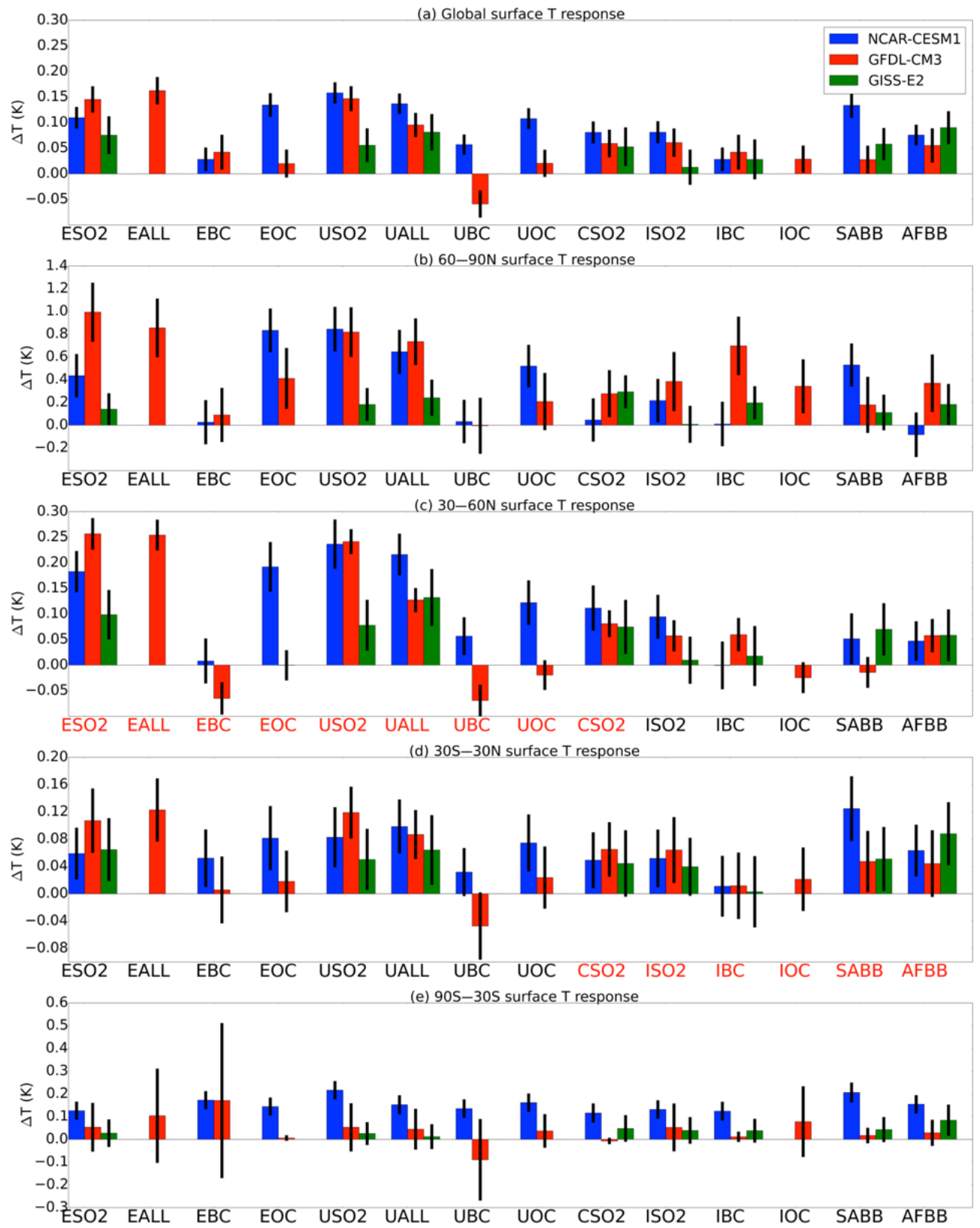

Figure 3. Global annual mean (a) and regional mean by latitude band (b-e) surface temperature responses (K) to each of the 14 aerosol perturbation simulations. Error bars show \pm 2 standard errors of the mean to assess statistical significance. Regions that are "local" to the given latitude band are in red. See Table 1 for definition of abbreviations. Note the different scales in each panel.

$0.2 \mathrm{~K}$. Global mean TXx is only statistically significant for the ESO2 in GFDL CM3 and CESM1, USO2 for CESM1, and ISO2 for GFDL CM3. Changes in the extreme temperatures over the Arctic (Fig. 5b) are close to zero and statistically insignificant, in contrast to Arctic mean temperature, which was heavily affected by many of the remote aerosol perturbations, though this is primarily caused by the seasonal dependence of Arctic amplification, as described above. TXx responses in the NHMLs (Fig. 5c) are dominated by local aerosol perturbations, reaching statistically signif- icant increases of up to $0.4 \mathrm{~K}$, while remote perturbations have no statistical significance. In the tropics and the Southern Hemisphere (Fig. 5d and e), there is almost no significant response in TXx to any aerosol perturbation. We conclude that although extreme temperature can be increased by remote aerosol perturbations in a few cases, in general the local forcing is a much greater control on extreme temperature, and remote responses are not nearly as large or significant for TXx compared to mean surface temperatures. 
(a) $\triangle \mathrm{TXX}$ GFDL US $\mathrm{SO}_{2}$

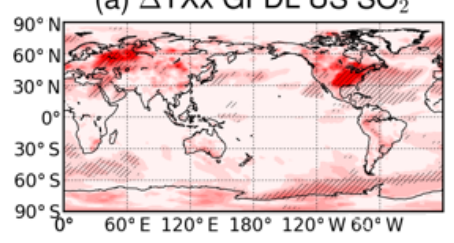

(d) $\triangle \mathrm{TXX}$ GFDL EU SO $\mathrm{SO}_{2}$

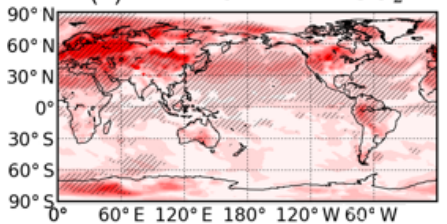

(g) $\triangle \mathrm{TXx}$ GFDL Ch $\mathrm{SO}_{2}$

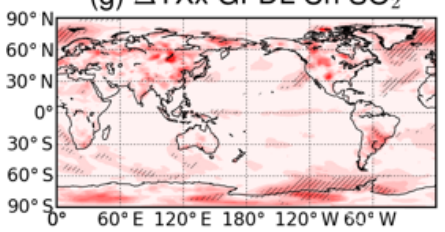

(j) $\triangle \mathrm{TXX}$ GFDL In $\mathrm{SO}_{2}$

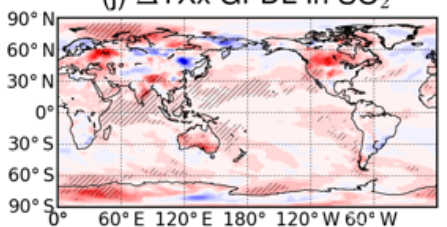

(I) $\triangle \mathrm{TXx}$ GFDL In BC

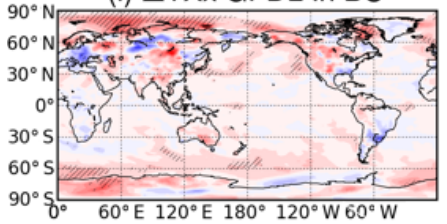

(n) $\triangle T X x$ GFDL EU BC

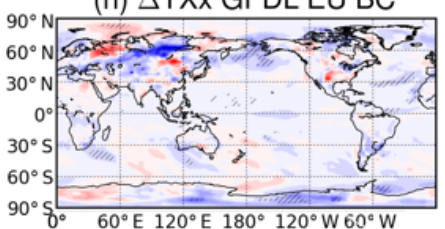

(b) $\triangle \mathrm{TXX} \mathrm{NCAR}$ US $\mathrm{SO}_{2}$

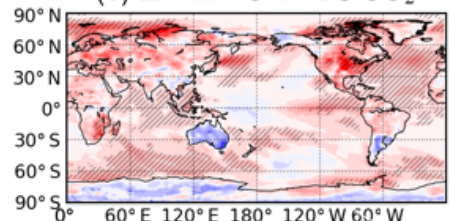

(e) $\triangle \mathrm{TX} \times \mathrm{NCAR} \mathrm{EU} \mathrm{SO}_{2}$

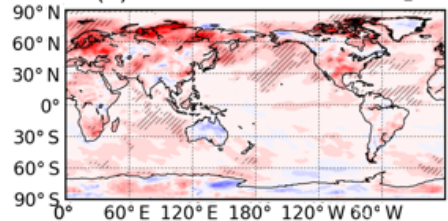

(h) $\triangle \mathrm{TXX}$ NCAR Ch SO

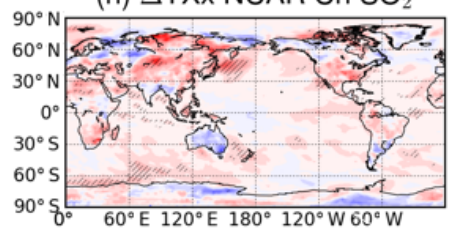

(k) $\triangle \mathrm{TXX}$ NCAR In $\mathrm{SO}_{2}$

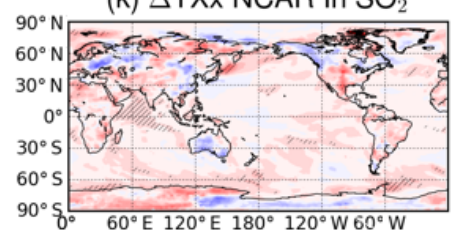

(m) $\triangle \mathrm{TXx}$ NCAR In BC

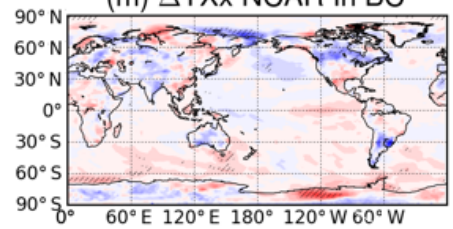

(c) $\triangle \mathrm{TXX}$ GISS US $\mathrm{SO}_{2}$

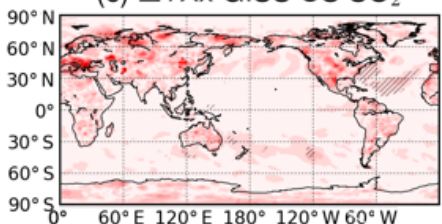

(f) $\triangle \mathrm{TXx}$ GISS EU SO

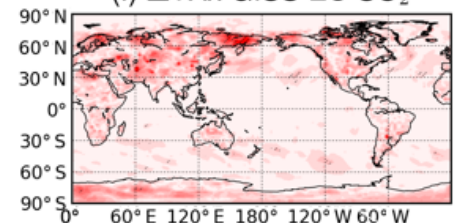

(i) $\triangle \mathrm{TXx}$ GISS Ch $\mathrm{SO}_{2}$

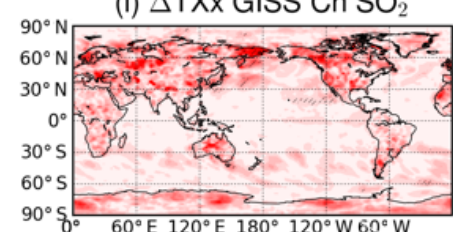

$90^{\circ} \mathrm{S} 0^{\circ} 60^{\circ} \mathrm{E} 120^{\circ} \mathrm{E} 180^{\circ} 120^{\circ} \mathrm{W} 60^{\circ} \mathrm{W}$

0.6

0.3

$-0.0 \quad \longleftarrow$

$-0.3$

$-0.6$

$-0.9$

Figure 4. The 200-year annual extreme temperature (TXx) responses (K) to aerosol emissions decreases in each of the three models (GFDL CM3, first column; NCAR CESM1, second column; GISS-E2, third column) for several different regional emissions decreases (simulations indicated in figure titles; see Table 1). Hatching represents statistical significance at the $95 \%$ level according to a Student $t$ test with the false discovery rate method from Wilks (2016) applied.

Figure 6 shows the eastern US and global mean surface temperature probability density function for each model for the control simulation and USO2 perturbation. Each probability density function has been normalized such that the area under the curve is equal to unity. The bars represent the actual probability density for each temperature value, whereas the dashed curve is a fitted Gaussian kernel density estimation of the probably density. In each model both globally and regionally, there is a clear shift in the mean of the distribution, resulting in additional occurrence of temperature extremes. Each mean shift is also statistically significant at the $95 \%$ confidence level, except for the eastern US regional temper- 

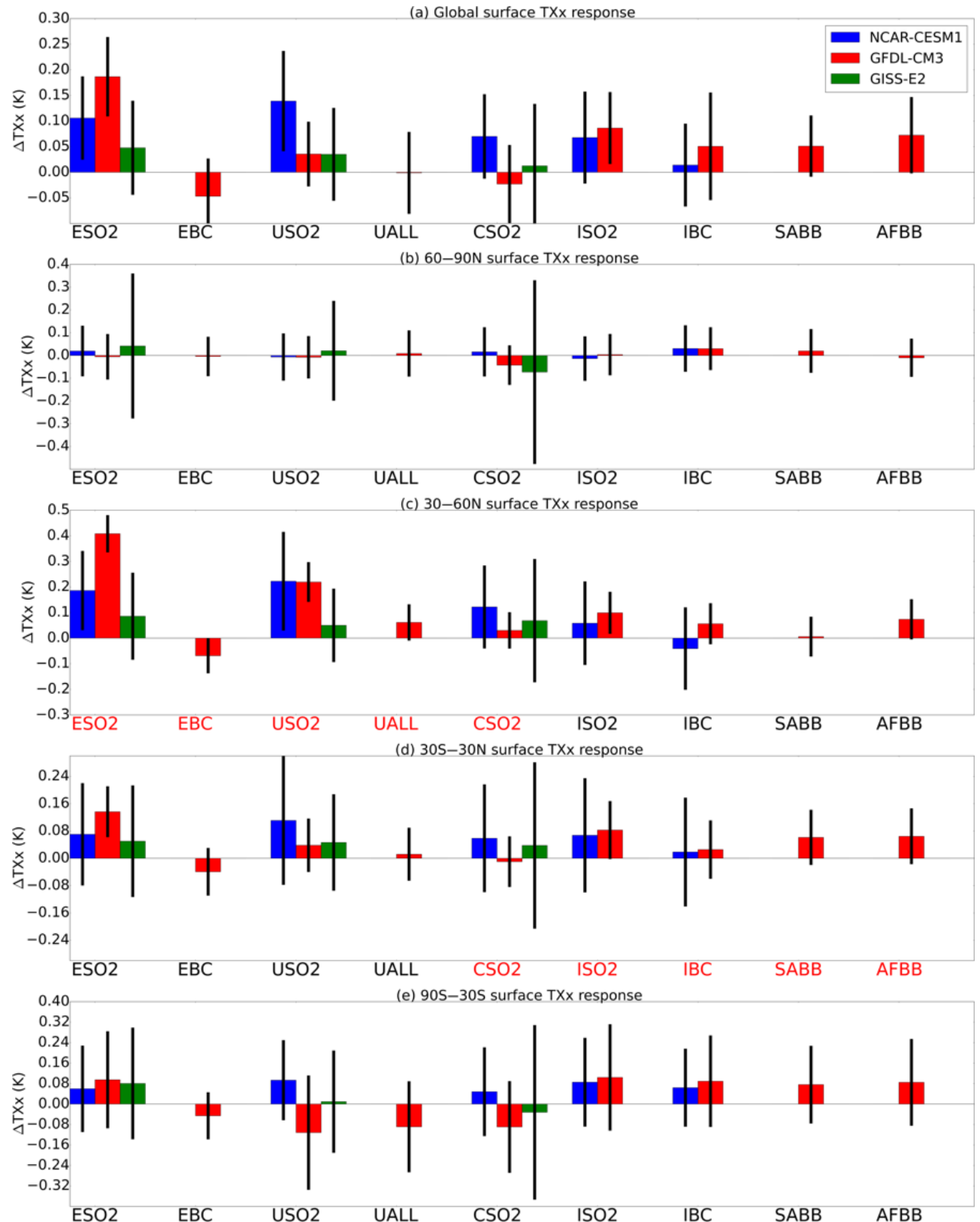

Figure 5. Global annual mean (a) and regional mean by latitude band (b-e) extreme temperature responses (K) to each of the 14 aerosol perturbation simulations. Error bars show \pm 2 standard errors of the mean to assess statistical significance. See Table 1 for definition of abbreviations.

ature distributions in GISS-E2. For the spatial average over the eastern US, the shape of the distributions remains unimodal and not skewed in GISS-E2 and GFDL CM3, except for CESM1, which is not skewed in the control simulation but skewed in the perturbation. Global mean temperature distributions are consistently bimodal in the control simulation and perturbation and generally not skewed. Overall, distribution shapes are mostly consistent, indicating that a mean shift is the statistical mechanism behind the increased temperature extremes.

\section{Effective radiative forcing and climate sensitivity}

\subsection{Effective radiative forcing and surface temperature response}

We use $\sim 80$-year fixed-SST and SIC atmosphere-only simulations in each of the three models to diagnose ERF due to each aerosol emissions perturbation. The global mean ERF from the 34 simulations ranges from about -0.1 to $0.3 \mathrm{~W} \mathrm{~m}^{-2}$, though all but six simulations (several of the 

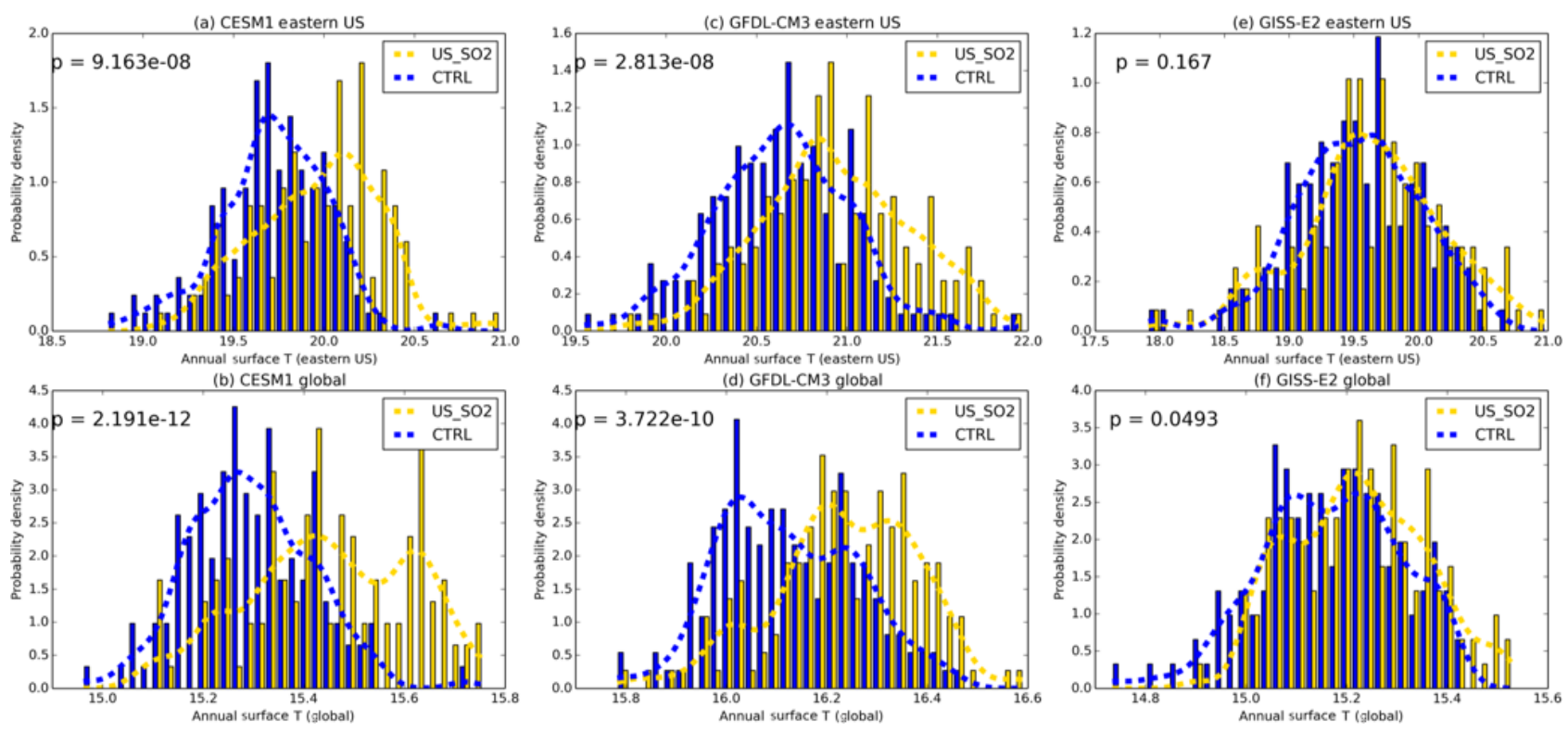

Figure 6. Eastern US regional $(\mathbf{a}, \mathbf{c}, \mathbf{e})$ and global mean $(\mathbf{b}, \mathbf{d}, \mathbf{f})$ probability density function for control and perturbation simulations in each model (columns). Dashed line is the Gaussian kernel density estimation for the normalized probability density function.

BC emissions perturbations) have ERF greater than zero. In Fig. 7, we plot global mean surface temperature response from the $\sim 200$-year coupled model simulations against global mean ERF for every perturbation simulation. We find a strong positive correlation among all models $(r=0.64$ for CESM1, $r=0.79$ for GFDL CM3, and $r=0.76$ for GISSE2), consistent with previous studies (Liu et al., 2018; Marvel et al., 2016). There is substantial overlap and a similar slope for all three models $\left(\sim 0.4 \mathrm{~K}\left(\mathrm{~W} \mathrm{~m}^{-2}\right)^{-1}\right)$, indicating that, on a global mean basis, the models are each similarly sensitive to regional aerosol forcing. We further analyze the climate sensitivity to aerosol forcing in the following section.

\subsection{Global climate sensitivity to regional aerosol perturbations and global $\mathrm{CO}_{2}$ doubling}

For a selection of simulations in which the aerosol ERF was statistically significant, we calculate in Fig. 8 the climate sensitivity parameter $\left(\mathrm{K}\left(\mathrm{W} \mathrm{m}^{-2}\right)^{-1}\right)$ to the regional aerosol perturbations as the quotient between the equilibrium global surface temperature response from the coupled model simulations and global ERF using the fixed-SST approach, similar to the equilibrium climate sensitivity (ECS) approach used for $\mathrm{CO}_{2}$. We also present the equilibrium climate sensitivity to a doubling of $\mathrm{CO}_{2}\left(2 \times \mathrm{CO}_{2}\right)$ in each of the three models using the same fixed-SST methodology for comparison to the aerosol climate sensitivity. We find that the climate sensitivity parameter for aerosol perturbations varies by model and by forcing, but mostly ranges from about 0.5 to $1.0 \mathrm{~K}\left(\mathrm{~W} \mathrm{~m}^{-2}\right)^{-1}$ in each of the three models, which is comparable to the values for $\mathrm{CO}_{2}$ sensitivity of approximately $1.0 \mathrm{~K}\left(\mathrm{~W} \mathrm{~m}^{-2}\right)^{-1}$ in GFDL CM3 and CESM1

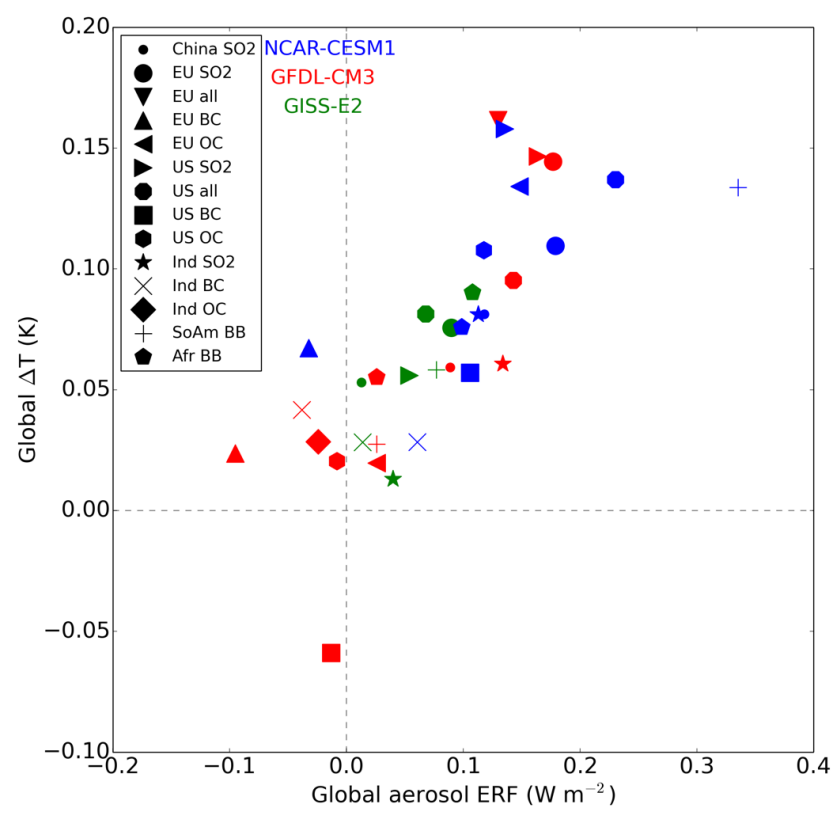

Figure 7. Scatterplot of global mean surface temperature response (K) to regional aerosol perturbations (symbols) versus global mean effective radiative forcing in each model (green: GISS-E2; red: GFDL CM3; blue: NCAR CESM1).

and $0.5 \mathrm{~K}\left(\mathrm{~W} \mathrm{~m}^{-2}\right)^{-1}$ in GISS-E2. Surface temperature appears to be most sensitive to European $\mathrm{SO}_{2}$ emissions in GFDL CM3, US $\mathrm{SO}_{2}$ emissions in CESM1, and US ALL $\left(\mathrm{SO}_{2}, \mathrm{BC}\right.$, and OA combined) emissions in GISS-E2. The $2 \times \mathrm{CO}_{2}$ climate sensitivity and the aerosol climate sensitivity for European $\mathrm{SO}_{2}$, European ALL, and $\mathrm{US} \mathrm{SO}_{2}$ are approxi- 
mately equivalent at about $1.0 \mathrm{~K}\left(\mathrm{~W} \mathrm{~m}^{-2}\right)^{-1}$ for GFDL CM3 and CESM1. The aerosol climate sensitivity is also in good agreement (overlapping error bars in Fig. 8) for the US $\mathrm{SO}_{2}$ emissions perturbation between the three models. However, the aerosol climate sensitivity is often substantially greater than $2 \times \mathrm{CO}_{2}$ climate sensitivity in GISS-E2, consistent with results from Marvel et al. (2016), discussed further below. Differences between aerosol climate sensitivity and $2 \times \mathrm{CO}_{2}$ climate sensitivity can be explained by the differences in both the temperature response and the associated ERF for each perturbation. In particular, ERF may be quite different between heterogeneous forcing agents relatively smaller in magnitude such as regional aerosols and large, more globally homogeneous forcing agents such as $\mathrm{CO}_{2}$. Using 11 models including GISS-E2, Smith et al. (2018) found that rapid adjustments reduce the ERF for $\mathrm{BC}$ aerosol but increase the ERF for $\mathrm{CO}_{2}$ forcing, consistent with the hypothesis that differences in ERF can explain differences in the temperature sensitivities shown in Fig. 8.

Previous work by Marvel et al. (2016) and Hansen et al. (2005) using only the GISS-E2 climate model found that the forcing efficacy of global aerosol reductions is greater than that of $\mathrm{CO}_{2}$. We extend this finding for GISS-E2 to regional aerosol emissions reductions, as the climate sensitivity parameter in all but one of our regional aerosol perturbation simulations in GISS-E2 is larger than the $2 \times \mathrm{CO}_{2}$ perturbation. In contrast, the aerosol climate sensitivity parameter in both GFDL CM3 and CESM1 is smaller than or about equal to that of $2 \times \mathrm{CO}_{2}$. We can conclude at minimum that aerosol forcing efficacy is model dependent, especially for regional aerosol perturbations, and this further highlights the importance of using multiple models to estimate or constrain estimates of ECS that include forcing from a diverse set of agents. The CMIP6 experiments may be used to shed further light on the relative efficacy of aerosol and greenhouse gas forcing, though not for regional perturbations.

\subsection{Regional temperature potential}

In addition to the global temperature response and global ERF, we also estimate the regional temperature sensitivities. We use the approach of Shindell (2012), who introduced regional temperature potential (RTP) coefficients. These coefficients account for the spatial heterogeneity of aerosol forcing and temperature response and can be derived for any pair of response regions and forcing regions. Following the methods of Shindell (2012) and Lewinschal et al. (2019), we calculate, within each latitude band, the temperature response to regional aerosol perturbations as a function of the latitude band averaged ERF containing each aerosol perturbation region. We then normalize this quantity by the global mean equilibrium temperature response to global mean forcing, resulting in a dimensionless coefficient giving the equilibrium temperature response in latitude band $x$ to forcing in region $y$. The response latitude band $x$ can be any of the bands de-
Table 2. Regional temperature potential (RTP) values for GFDL CM3 for simulations with statistically significant ERF and temperature response.

\begin{tabular}{|c|c|c|c|c|}
\hline & $\begin{array}{r}60-90^{\circ} \mathrm{N} \\
(\text { Arctic) }\end{array}$ & $\begin{array}{l}30-60^{\circ} \mathrm{N} \\
(\mathrm{NHMLs})\end{array}$ & $\begin{array}{r}30^{\circ} \mathrm{S}-30^{\circ} \mathrm{N} \\
(\text { tropics })\end{array}$ & $\begin{array}{r}30-90^{\circ} \mathrm{S} \\
(\mathrm{SH})\end{array}$ \\
\hline $\mathrm{CSO} 2$ & 1.86 & 0.54 & 0.44 & 0.05 \\
\hline ESO2 & 2.26 & 0.58 & 0.24 & 0.12 \\
\hline EALL & 1.29 & 0.38 & 0.18 & 0.16 \\
\hline USO2 & 1.43 & 0.42 & 0.21 & 0.09 \\
\hline UALL & 1.87 & 0.32 & 0.22 & 0.11 \\
\hline ISO2 & 2.98 & 0.45 & 0.50 & 0.41 \\
\hline SABB & 4.57 & 0.36 & 1.21 & 0.44 \\
\hline AFBB & 2.15 & 0.34 & 0.26 & 0.17 \\
\hline
\end{tabular}

Table 3. Regional temperature potential (RTP) values for GISS-E2 for simulations with statistically significant ERF and temperature response.

\begin{tabular}{lrrrr}
\hline & $\begin{array}{r}60-90^{\circ} \mathrm{N} \\
(\text { Arctic) }\end{array}$ & $\begin{array}{r}30-60^{\circ} \mathrm{N} \\
(\mathrm{NHMLs})\end{array}$ & $\begin{array}{r}30^{\circ} \mathrm{S}-30^{\circ} \mathrm{N} \\
\text { (tropics) }\end{array}$ & $\begin{array}{r}30-90^{\circ} \mathrm{S} \\
(\mathrm{SH})\end{array}$ \\
\hline $\mathrm{CSO} 2$ & 1.34 & 0.34 & 0.16 & 0.22 \\
$\mathrm{ESO} 2$ & 0.62 & 0.43 & 0.23 & 0.12 \\
$\mathrm{USO} 2$ & 0.87 & 0.37 & 0.16 & 0.12 \\
$\mathrm{UALL}$ & 0.80 & 0.44 & 0.15 & 0.04 \\
SABB & 0.97 & 0.61 & 0.42 & 0.37 \\
AFBB & 0.98 & 0.31 & 0.44 & 0.45 \\
\hline
\end{tabular}

fined in Fig. 2, whereas forcing regions $y$ are the latitude bands containing each of our 14 regional aerosol perturbation locations, either $30-60^{\circ} \mathrm{N}$ (NHMLs) or $30^{\circ} \mathrm{S}-30^{\circ} \mathrm{N}$ (tropics). As defined in Shindell (2012), RTP for a given pair of regions is

$\mathrm{RTP}=\frac{\mathrm{d} T_{x}}{\mathrm{~d} F_{y}} / \frac{\mathrm{d} T_{\text {global }}}{\mathrm{d} F_{\text {global }}}$,

where $\mathrm{d} T$ is change in temperature and $\mathrm{d} F$ is change in ERF. Because of the normalization by global mean temperature and global mean ERF, the RTP coefficients are unitless.

RTP coefficients in each latitude band for a given aerosol perturbation region are reported in Table 2 for GFDL CM3, Table 3 for GISS-E2, and Table 4 for CESM1. We present only RTP values for which the corresponding ERF and temperature response were statistically significant or for which data were available. The India, South America, and Africa entries in Tables 2-4 are based on a forcing average from the tropics since that region contains almost all of the statistically significant signal. All other values are based on the NHML latitude band forcing average. Higher values of RTP indicate higher sensitivity of the particular response region to the aerosol forcing regions. RTP values from individual models provide a range of possible estimates. Figure 9 shows the multi-model mean RTP coefficients for a selection of regional aerosol perturbation simulations, along with the mean 


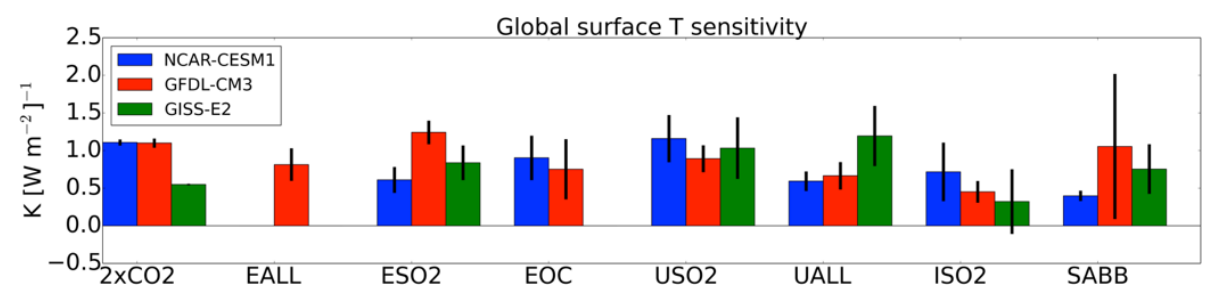

Figure 8. Global climate sensitivity to regional aerosol emissions perturbations and to a doubling of $\mathrm{CO}_{2}\left(2 \times \mathrm{CO}_{2}\right)$ in each model. Error bars represent \pm 2 standard errors around the mean. See Table 1 for definition of abbreviations.

Table 4. Regional temperature potential (RTP) values for CESM1 for simulations with statistically significant ERF and temperature response.

\begin{tabular}{|c|c|c|c|c|}
\hline & $\begin{array}{r}60-90^{\circ} \mathrm{N} \\
(\text { Arctic) }\end{array}$ & $\begin{array}{l}30-60^{\circ} \mathrm{N} \\
(\mathrm{NHMLs})\end{array}$ & $\begin{array}{r}30^{\circ} \mathrm{S}-30^{\circ} \mathrm{N} \\
(\text { tropics) }\end{array}$ & $\begin{array}{r}30-90^{\circ} \mathrm{S} \\
(\mathrm{SH})\end{array}$ \\
\hline USO2 & 2.02 & 0.57 & 0.20 & 0.52 \\
\hline AFBB & 1.29 & 0.72 & 0.97 & 2.37 \\
\hline
\end{tabular}

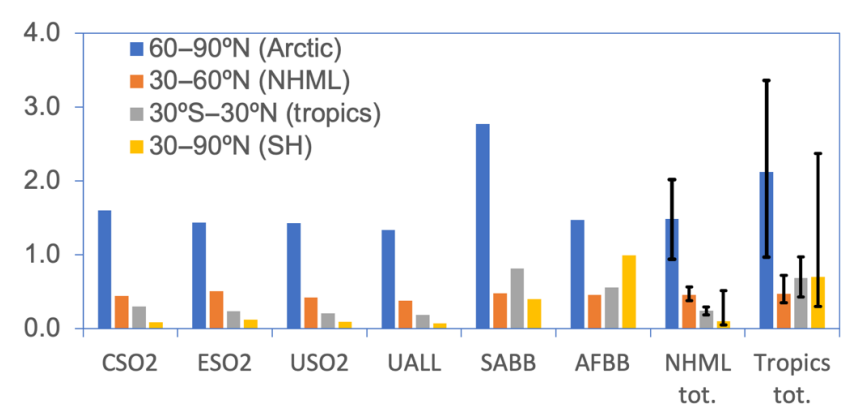

Figure 9. Regional temperature potential (RTP) coefficients (unitless) for the multi-model mean between GFDL CM3, GISS-E2, and CESM1 for select simulations and the average by forcing region (e.g., "NHML tot." and "Tropics tot."). Uncertainty bars in the last two columns indicate the range of the RTP values as reported by the three models.

of the NHMLs and tropics perturbations grouped together ("NHML tot.", "tropics tot."). Figure 9 indicates that the response to NHML forcing is consistent in all response regions regardless of where the aerosol forcing is longitudinally located within the NHMLs, as indicated by the similar RTP magnitudes in the first four clusters of bars (CSO2, ESO2, USO2, and UALL). Consistent with our earlier findings in Fig. 2, the Arctic always emerges as the most sensitive region to nonlocal aerosol forcing. After the Arctic, regional sensitivities are greatest for the NHMLs, tropics, and Southern Hemisphere (SH) for perturbations in the NHMLs (e.g., CSO2, ESO2, USO2, UALL). For tropical perturbations such as ISO2, SABB, and AFBB, either the SH or the tropics are most sensitive, after the Arctic. Across each of the aerosol perturbations, the RTP coefficients are similar in magnitude when grouped by similar latitudinal forcing locations.
Our findings are similar to those of Shindell (2012), but we find a higher sensitivity in the Arctic to NHML forcing (1.49, Fig. 9 "NHML tot." versus RTP of 0.43 in Shindell, 2012). Shindell (2012) finds the Arctic is most sensitive to local forcing but we lack a perturbation simulation to diagnose that response here. Shindell (2012) reported an Arctic RTP for tropical forcing of 0.36, close to that of NHML forcing, indicating that aerosol perturbations in the tropics are also important for Arctic climate response, which qualitatively agrees with our findings in Fig. 9. Averaging the RTP values corresponding to statistically significant ERF and temperature response within a single latitude band (for example, average RTP of USO2, ESO2, and CSO2) yields a close match with Shindell (2012) RTP values, especially in the NHMLs and tropics. Shindell (2012) reports an RTP of 0.49 for NHML response to NHML forcing, very close to the average of our NHML forcings in Fig. 9, which is 0.46 (orange bar in Fig. 9 for "NHML tot."). The other response regions (tropics and Southern Hemisphere) compare moderately well with Shindell (2012) for NHML forcing ( 0.25 versus 0.15 for the tropics and 0.1 versus 0.05 for the Southern Hemisphere). Shindell (2012) used an older model and an idealized forcing through an entire latitude band as opposed to our more realistic localized forcing, which may account for some of the differences in each region.

The uncertainty range in the final two clusters of bars in Fig. 9 gives the range of RTP values for the total NHML forcing using the model individual values to construct a high and low estimate. For the NHML forcing cases, which include $\mathrm{USO} 2, \mathrm{CSO} 2$, and $\mathrm{ESO} 2$, the responses are robust across our models and there is little intermodel variation, as indicated by the small uncertainty range in each of the four response regions under "NHML tot.". For the tropical forcing cases, the models diverge (uncertainty bars under "Tropics tot." in Fig. 9), especially in the regions remote to the tropics. These results imply that the use of RTP coefficients or similar simple climate response metrics for remote responses to forcing in NHML regions are more robust and reliable than those for remote responses to forcing in tropical regions. 


\section{Summary and conclusions}

Using three coupled chemistry-climate models, we conduct 160-240-year simulations in which aerosols of a specific type and from a specific region are set to zero (or greatly reduced) and compare to an otherwise identical control simulation in order to estimate the mean and extreme temperature response to regional aerosol emissions reductions. We estimate both the near-source local climate response and the remote response to regional aerosol emissions for both mean and extreme temperatures. Removal of regional aerosol emissions almost universally results in warming both globally and regionally, with some exceptions including perturbations of black carbon, an absorbing aerosol species. Surface warming is largest and most robust across models in response to $\mathrm{SO}_{2}$ emissions reductions, particularly $\mathrm{SO}_{2}$ from Europe and the US. Using a sign and significance approach to assessing robustness, we estimate that about $81 \%$ of the global surface area has a robust surface temperature response to European $\mathrm{SO}_{2}$ reduction. All perturbations except for Indian BC have a spatial robustness of greater than $50 \%$. Furthermore, the magnitudes of the responses are in agreement (overlapping ranges in globally and regionally averaged temperature responses in most perturbation simulations) in CESM1 and GFDL CM3, but temperature changes are smaller in GISSE2 due to weaker aerosol forcing. We find both local and remote statistically significant regional climate responses to regional aerosol emissions perturbations. Local emissions perturbations exert a strong warming response in the Northern Hemisphere midlatitude (NHML) regions including the US and Europe. Aerosol emission reductions from all world regions that we considered significantly increase mean temperature in the Arctic by up to $1 \mathrm{~K}$ (for emissions perturbations from Europe). Emissions reductions from the NHMLs exert a warming response in the tropics that rivals the magnitude of the response to emissions perturbations that are local to the tropics.

We assess the climate sensitivity to aerosol perturbations in each model and find a range from about 0.5 to $1.0 \mathrm{~K}\left(\mathrm{~W} \mathrm{~m}^{-2}\right)^{-1}$. The aerosol climate sensitivity varies by type of forcing (e.g., $\mathrm{SO}_{2}, \mathrm{OA}, \mathrm{BC}$ ) and also magnitude of forcing and can be different than the $2 \times \mathrm{CO}_{2}$ climate sensitivity, due to differences between a heterogeneous, localized aerosol forcing and a more homogeneous $\mathrm{CO}_{2}$ forcing. Though it has been argued that uncertainty in aerosol forcing is the major factor in uncertainty of estimates of climate sensitivity to $\mathrm{CO}_{2}$ based on modern observations (Andreae et al., 2005), less attention has been given to the temperature sensitivity to aerosol forcing itself, in response to both global and regional aerosol perturbations. In contrast to previous findings using global aerosol reductions (Hansen, 2005; Marvel et al., 2016), we find that the climate sensitivity to aerosol forcing is less than or equal to the climate sensitivity to a doubling of $\mathrm{CO}_{2}$ in two of three models, indicating a strong dependence on both model choice and region of aerosol reduc- tion. Future work using the CMIP6 simulations may shed light on forcing efficacy of global aerosol reductions using a large number of models.

We estimate updated RTP coefficients in order to help facilitate estimation of climate impact metrics at a sub-global scale. These updated RTP coefficients may be useful for integrated assessment modeling (IAM), such as the Long-range Energy Alternatives Planning system - Integrated Benefits Calculator (LEAP-IBC) (Heaps 2016), to calculate climate impacts across a range of emissions scenarios quickly and efficiently. We improve on previous studies by providing RTP coefficients for multiple models and for a large variety of aerosol types and regional perturbations and by narrowing the forcing region from latitudinal bands to specific countries or continents (e.g., US $\mathrm{SO}_{2}$, European $\mathrm{SO}_{2}$ ). We provide a multimodel mean RTP as well as the range represented by individual models. We find that the regional temperature response to Northern Hemisphere midlatitude forcing is largely independent of longitudinal forcing location within the NHMLs. We also find a small range of intermodel variability in regional temperature response to NHML forcing, indicating robustness of the RTP coefficients. For aerosol forcing occurring in the NHMLs, our reported RTP coefficients are similar to those reported in Shindell (2012), except for the response in the Arctic, which we find to be more sensitive to NHML forcing. Our results indicate that RTP coefficients for Arctic response to aerosol forcing in the Arctic may need to be revised upwards, which has implications for climate impacts and integrated assessment modeling applications. Further unexpected warming in the Arctic from the unmasking of aerosol forcing could bring about Arctic climate tipping points such as permafrost thawing even sooner than currently projected. Future work will link climate responses directly to emissions changes for each of our models, similar to what has been done for NorESM in Lewinschal et al. (2019).

We also consider the extreme temperature response to regional aerosol perturbations and find that by shifting the overall surface temperature distribution, aerosol perturbations increase the warming extremes (upper tail of the surface temperature distribution). The annual maximum of maximum daily temperatures, or TXx, increases by about 0.1 to $0.2 \mathrm{~K}$ globally, closely mirroring the global changes in mean surface temperature, suggesting a mean shift of the temperature distribution to warmer temperatures, with limited impact on the shape of the distribution mainly occurring in only one of our models. We find the mean shift to be statistically significant on a global mean basis in all models and regionally in two of the three models. Compared to mean surface temperatures, extreme temperatures are not very sensitive to remote aerosol perturbations, with a few exceptions.

The understanding of the major drivers of projected regional climate change is key information needed by the climate assessment and impact community. Our results have the potential to provide a framework for a key methodolog- 
ical link between physical science and impacts, adaptation, and vulnerability analysis. This work is a first step towards providing statistical relationships between the changes in regional aerosol emissions and the statistically significant changes in climate that can be attributed to them. Such relationships would allow for the generation of regional climate change scenarios without having to simulate computationally demanding chemistry-climate models.

Code availability. The code for the atmospheric component of the GFDL CM3 model is available here: https://www.gfdl.noaa.gov/ am3/ (GFDL Model Development Team, 2020). NCAR CESM1 model code is available here: http://www.cesm.ucar.edu/models/ cesm1.0/ (University Corporation for Atmospheric Research (UCAR), 2020). GISS-E2 model code is available here: https:// simplex.giss.nasa.gov/snapshots/ (Aleinov and Schmidt, 2020).

Data availability. RTP coefficients have been provided here: https://figshare.com/articles/RTP_coefficients_Westervelt_et_al_ ACP/10669322 (Westervelt, 2019a). Global and regional temperature response model data used in the figures is provided here: https://figshare.com/articles/Global_mean_T_by_latitude_band/ 10710722 (Westervelt, 2019b). Contact the corresponding author for any other data requests.

Supplement. The supplement related to this article is available online at: https://doi.org/10.5194/acp-20-3009-2020-supplement.

Author contributions. DMW wrote the manuscript and created all figures. NRM performed ERF simulations and contributed extremes analysis. AMF, DTS, and JFL originally conceived the project, with later input from DMW, AJC, MP, and LWH. GF, AJC, and GC conducted simulations and transferred data. All authors contributed to editing the manuscript.

Competing interests. The authors declare that they have no conflict of interest.

Disclaimer. The authors declare no conflicts of interest, and views, opinions, and findings presented in this paper are solely those of the authors and do not reflect the views of the funding agency.

Acknowledgements. The NCAR CESM work is supported by the National Science Foundation and the Office of Science (BER) of the U.S. Department of Energy. NCAR is sponsored by the National Science Foundation. GISS-E2-R simulations used resources provided by the NASA High-End Computing (HEC) program through the NASA Center for Climate Simulation (NCCS) at Goddard Space Flight Center. We acknowledge Claudia Tebaldi for useful discussions on statistical methods and temperature extremes.
Financial support. This research has been supported by the National Science Foundation, Directorate for Geosciences (grant no. AGS 14-19398).

Review statement. This paper was edited by Pedro JimenezGuerrero and reviewed by two anonymous referees.

\section{References}

Albrecht, B. A.: Aerosols, Cloud Microphysics, and Fractional Cloudiness, Science, 245, 1227-1230, https://doi.org/10.1126/science.245.4923.1227, 1989.

Aleinov, I. and Schmidt, G.: NASA GISS ModelE, available at: https://simplex.giss.nasa.gov/gcm/, last access: 10 March 2020.

Allen, R. J.: A 21st century northward tropical precipitation shift caused by future anthropogenic aerosol reductions, J. Geophys. Res.-Atmos., 120, 9087-9102, https://doi.org/10.1002/2015JD023623, 2015.

Allen, R. J., Amiri-Farahani, A., Lamarque, J.-F., Smith, C., Shindell, D., Hassan, T., and Chung, C. E.: Observationally constrained aerosol-cloud semi-direct effects, Clim. Atmos. Sci., 2, 16, https://doi.org/10.1038/s41612-019-0073-9, 2019.

Andreae, M. O., Jones, C. D., and Cox, P. M.: Strong present-day aerosol cooling implies a hot future, Nature, 435, 1187-1190, https://doi.org/10.1038/nature03671, 2005.

Arrhenius, S.: On the influence of carbonic acid in the air upon the temperature of the ground, Philos. Mag. Ser., 5, 41, 237-276, https://doi.org/10.1080/14786449608620846, 1896.

Bond, T. C., Doherty, S. J., Fahey, D. W., Forster, P. M., Berntsen, T., DeAngelo, B. J., Flanner, M. G., Ghan, S., Kärcher, B., Koch, D., Kinne, S., Kondo, Y., Quinn, P. K., Sarofim, M. C., Schultz, M. G., Schulz, M., Venkataraman, C., Zhang, H., Zhang, S., Bellouin, N., Guttikunda, S. K., Hopke, P. K., Jacobson, M. Z., Kaiser, J. W., Klimont, Z., Lohmann, U., Schwarz, J. P., Shindell, D., Storelvmo, T., Warren, S. G., and Zender, C. S.: Bounding the role of black carbon in the climate system: A scientific assessment, J. Geophys. Res.-Atmos., 118, 5380-5552, https://doi.org/10.1002/jgrd.50171, 2013.

Callendar, G. S.: The artificial production of carbon dioxide and its influence on temperature, Q. J. Roy. Meteor. Soc., 64, 223-240, https://doi.org/10.1002/qj.49706427503, 1938.

University Corporation for Atmospheric Research (UCAR): Community Earth System Model version 1.0, available at: http: //www.cesm.ucar.edu/models/cesm1.0/, last access: 10 March 2020.

Conley, A. J., Westervelt, D. M., Lamarque, J.-F., Fiore, A. M., Shindell, D., Correa, G., Faluvegi, G., and Horowitz, L. W.: Multimodel Surface Temperature Responses to Removal of U.S. Sulfur Dioxide Emissions, J. Geophys. Res.-Atmos., 123, 2773 2796, https://doi.org/10.1002/2017JD027411, 2018.

Cox, P. M., Huntingford, C., and Williamson, M. S.: Emergent constraint on equilibrium climate sensitivity from global temperature variability, Nature, 553, 319-322, https://doi.org/10.1038/nature25450, 2018.

Donner, L. J., Wyman, B. L., Hemler, R. S., Horowitz, L. W., Ming, Y., Zhao, M., Golaz, J.-C., Ginoux, P., Lin, S.-J., Schwarzkopf, M. D., Austin, J., Alaka, G., Cooke, W. F., Delworth, T. L., 
Freidenreich, S. M., Gordon, C. T., Griffies, S. M., Held, I. M., Hurlin, W. J., Klein, S. A., Knutson, T. R., Langenhorst, A. R., Lee, H.-C., Lin, Y., Magi, B. I., Malyshev, S. L., Milly, P. C. D., Naik, V., Nath, M. J., Pincus, R., Ploshay, J. J., Ramaswamy, V., Seman, C. J., Shevliakova, E., Sirutis, J. J., Stern, W. F., Stouffer, R. J., Wilson, R. J., Winton, M., Wittenberg, A. T., and Zeng, F.: The Dynamical Core, Physical Parameterizations, and Basic Simulation Characteristics of the Atmospheric Component AM3 of the GFDL Global Coupled Model CM3, J. Climate, 24, 34843519, https://doi.org/10.1175/2011JCLI3955.1, 2011.

Fontes, T., Li, P., Barros, N., and Zhao, P.: Trends of $\mathrm{PM}_{2.5}$ concentrations in China: A long term approach, J. Environ. Manage., 196, 719-732, https://doi.org/10.1016/J.JENVMAN.2017.03.074, 2017.

GFDL Model Development Team: GFDL Atmospheric Model version 3, available at: https://www.gfdl.noaa.gov/am3/, last access: 10 March 2020.

Gillett, N. P. and Von Salzen, K.: The role of reduced aerosol precursor emissions in driving near-term warming, Environ. Res. Lett., 8, 034008, https://doi.org/10.1088/1748-9326/8/3/034008, 2013.

Hansen, J.: Efficacy of climate forcings, J. Geophys. Res., 110, D18104, https://doi.org/10.1029/2005JD005776, 2005.

Heaps, C. G.: Long-range Energy Alternatives Planning (LEAP) system [Software version: 2018.1.30], Stockholm Environment Institute, Somerville, MA, USA, available at: https://www. energycommunity.org (last access: 22 November 2019), 2016.

Horton, R. M., Mankin, J. S., Lesk, C., Coffel, E., and Raymond, C.: A Review of Recent Advances in Research on Extreme Heat Events, Curr. Clim. Chang. Reports, 2, 242-259, https://doi.org/10.1007/s40641-016-0042-x, 2016.

Huber, M., Beyerle, U., and Knutti, R.: Estimating climate sensitivity and future temperature in the presence of natural climate variability, Geophys. Res. Lett., 41, 2086-2092, https://doi.org/10.1002/2013GL058532, 2014.

IPCC (Intergovernmental Panel on Climate Change): Managing the Risks of Extreme Events and Disasters to Advance Climate Change Adaptation. A Special Report of Working Groups I and II of the Intergovernmental Panel on Climate Change, Cambridge University Press, Cambridge, UK, and New York, NY, USA, 582 pp., 2012.

Kasoar, M., Voulgarakis, A., Lamarque, J.-F., Shindell, D. T., Bellouin, N., Collins, W. J., Faluvegi, G., and Tsigaridis, K.: Regional and global temperature response to anthropogenic $\mathrm{SO}_{2}$ emissions from China in three climate models, Atmos. Chem. Phys., 16, 9785-9804, https://doi.org/10.5194/acp-169785-2016, 2016.

Kasoar, M., Shawki, D., and Voulgarakis, A.: Similar spatial patterns of global climate response to aerosols from different regions, Clim. Atmos. Sci., 1, 12, https://doi.org/10.1038/s41612018-0022-z, 2018.

Knutti, R. and Hegerl, G. C.: The equilibrium sensitivity of the Earth's temperature to radiation changes, Nat. Geosci., 1, 735743, https://doi.org/10.1038/ngeo337, 2008.

Knutti, R. and Rugenstein, M. A. A.: Feedbacks, climate sensitivity and the limits of linear models, Philos. T. R. Soc. A, 373, https://doi.org/10.1098/rsta.2015.0146, 2015.

Knutti, R., Rugenstein, M. A. A., and Hegerl, G. C.: Beyond equilibrium climate sensitivity, Nat. Geosci., 10, 727-736, https://doi.org/10.1038/NGEO3017, 2017.
Leibensperger, E. M., Mickley, L. J., Jacob, D. J., Chen, W.T., Seinfeld, J. H., Nenes, A., Adams, P. J., Streets, D. G., Kumar, N., and Rind, D.: Climatic effects of 1950-2050 changes in US anthropogenic aerosols - Part 1: Aerosol trends and radiative forcing, Atmos. Chem. Phys., 12, 3333-3348, https://doi.org/10.5194/acp-12-3333-2012, 2012.

Levy, H., Horowitz, L. W., Schwarzkopf, M. D., Ming, Y., Golaz, J.-C., Naik, V., and Ramaswamy, V.: The roles of aerosol direct and indirect effects in past and future climate change, J. Geophys. Res.-Atmos., 118, 4521-4532, https://doi.org/10.1002/jgrd.50192, 2013.

Lewinschal, A., Ekman, A. M. L., Hansson, H.-C., Sand, M., Berntsen, T. K., and Langner, J.: Local and remote temperature response of regional $\mathrm{SO}_{2}$ emissions, Atmos. Chem. Phys., 19, 2385-2403, https://doi.org/10.5194/acp-19-2385-2019, 2019.

Li, C., McLinden, C., Fioletov, V., Krotkov, N., Carn, S., Joiner, J., Streets, D., He, H., Ren, X., Li, Z., and Dickerson, R. R.: India Is Overtaking China as the World's Largest Emitter of Anthropogenic Sulfur Dioxide, Sci. Rep.-UK, 7, 14304, https://doi.org/10.1038/s41598-017-14639-8, 2017.

Liu, L., Shawki, D., Voulgarakis, A., Kasoar, M., Samset, B. H., Myhre, G., Forster, P. M., Hodnebrog, Ø., Sillmann, J., Aalbergsjø, S. G., Boucher, O., Faluvegi, G., Iversen, T., Kirkevåg, A., Lamarque, J.-F., Olivié, D., Richardson, T., Shindell, D., and Takemura, T.: A PDRMIP Multimodel Study on the Impacts of Regional Aerosol Forcings on Global and Regional Precipitation, J. Climate, 31, 4429-4447, https://doi.org/10.1175/JCLI-D-170439.1, 2018.

Lu, Z., Zhang, Q., and Streets, D. G.: Sulfur dioxide and primary carbonaceous aerosol emissions in China and India, 1996-2010, Atmos. Chem. Phys., 11, 9839-9864, https://doi.org/10.5194/acp-11-9839-2011, 2011.

Marvel, K., Schmidt, G. A., Miller, R. L., and Nazarenko, L. S.: Implications for climate sensitivity from the response to individual forcings, Nat. Clim. Chang., 6, 386-389, https://doi.org/10.1038/nclimate2888, 2016.

Mascioli, N. R., Fiore, A. M., Previdi, M., and Correa, G.: Temperature and Precipitation Extremes in the United States: Quantifying the Responses to Anthropogenic Aerosols and Greenhouse Gases, J. Climate, 29, 2689-2701, https://doi.org/10.1175/JCLID-15-0478.1, 2016.

Murphy, D.: Little net clear-sky radiative forcing from recent regional redistribution of aerosols, Nat. Geosci., 6, 258-262, https://doi.org/10.1038/ngeo1740, 2013.

Myhre, G., Shindell, D., Bréon, F.-M., Collins, W., Fuglestvedt, J., Huang, J., Koch, D., Lamarque, J.-F., Lee, D., Mendoza, B., Nakajima, T., Robock, A., Stephens, G., Takemura, T., and Zhang, H.: Anthropogenic and Natural Radiative Forcing, in: Climate Change 2013, The Physical Science Basis, Contribution of Working Group I to the Fifth Assessment Report of the Intergovernmental Panel on Climate Change, edited by: Stocker, T. F., Qin, D., Plattner, G.-K., Tignor, M., Allen, S. K., Boschung, J., Nauels, A., Xia, Y., Bex, V., and Midgley, P. M., Cambridge University Press, Cambridge, UK and New York, NY, USA, 2013.

Naik, V., Horowitz, L. W., Fiore, A. M., Ginoux, P., Mao, J., Aghedo, A. M., and Levy, H.: Impact of preindustrial to presentday changes in short-lived pollutant emissions on atmospheric composition and climate forcing, J. Geophys. Res.-Atmos., 118, 1-25, https://doi.org/10.1002/jgrd.50608, 2013. 
Neale, R. B., Gettelman, A., Park, S., Chen, C.-C., Lauritzen, P. H., Williams, D. L., and Taylor, M. A: Description of the NCAR Community Atmosphere Model (CAM 5.0), NCAR Technical Note TN-486+STR, Natl. Center for Atmospheric Research, available at: http://www.cesm.ucar.edu/ models/cesm1.0/cam/docs/description/cam5_desc.pdf (last access: 10 March 2020), 2012.

Otto, A., Otto, F. E. L., Boucher, O., Church, J., Hegerl, G., Forster, P. M., Gillett, N. P., Gregory, J., Johnson, G. C., Knutti, R., Lewis, N., Lohmann, U., Marotzke, J., Myhre, G., Shindell, D., Stevens, B., and Allen, M. R.: Energy budget constraints on climate response, Nat. Geosci., 6, 415-416, https://doi.org/10.1038/ngeo1836, 2013.

Persad, G. G. and Caldeira, K.: Divergent global-scale temperature effects from identical aerosols emitted in different regions, Nat. Commun., 9, 3289, https://doi.org/10.1038/s41467-018-058386, 2018.

Previdi, M., Liepert, B. G., Peteet, D., Hansen, J., Beerling, D. J., Broccoli, A. J., Frolking, S., Galloway, J. N., Heimann, M., Le Quéré, C., Levitus, S., and Ramaswamy, V.: Climate sensitivity in the Anthropocene, Q. J. Roy. Meteor. Soc., 139, 1121-1131, https://doi.org/10.1002/qj.2165, 2013.

Ramanathan, V. and Carmichael, G.: Global and regional climate changes due to black carbon, Nat. Geosci., 1, 221-227, https://doi.org/10.1038/ngeo156, 2008.

Raphael, M. N., Marshall, G. J., Turner, J., Fogt, R. L., Schneider, D., Dixon, D. A., Hosking, J. S., Jones, J. M., and Hobbs, W. R.: The Amundsen Sea Low: Variability, Change, and Impact on Antarctic Climate, B. Am. Meteorol. Soc., 97, 111-121, https://doi.org/10.1175/BAMS-D-14-00018.1, 2016.

Samset, B. H., Sand, M., Smith, C. J., Bauer, S. E., Forster, P. M., Fuglestvedt, J. S., Osprey, S., and Schleussner, C.F.: Climate Impacts From a Removal of Anthropogenic Aerosol Emissions, Geophys. Res. Lett., 45, 1020-1029, https://doi.org/10.1002/2017GL076079, 2018.

Samset, B. H., Lund, M. T., Bollasina, M., Myhre, G., and Wilcox, L.: Emerging Asian aerosol patterns, Nat. Geosci., 12, 582-584, https://doi.org/10.1038/s41561-019-0424-5, 2019.

Seneviratne, S. I., Phipps, S. J., Pitman, A. J., Hirsch, A. L., Davin, E. L., Donat, M. G., Hirschi, M., Lenton, A., Wilhelm, M., and Kravitz, B.: Land radiative management as contributor to regional-scale climate adaptation and mitigation, Nat. Geosci., 11, 88-96, https://doi.org/10.1038/s41561-017-0057-5, 2018.

Schmidt, G. A., Kelley, M., Nazarenko, L., Ruedy, R., Russell, G. L., Aleinov, I., Bauer, M., Bauer, S. E., Bhat, M. K., Bleck, R., Canuto, V., Chen, Y.-H., Cheng, Y., Clune, T. L., Del Genio, A., de Fainchtein, R., Faluvegi, G., Hansen, J. E., Healy, R. J., Kiang, N. Y., Koch, D., Lacis, A. A., LeGrande, A. N., Lerner, J., Lo, K. K., Matthews, E. E., Menon, S., Miller, R. L., Oinas, V., Oloso, A. O., Perlwitz, J. P., Puma, M. J., Putman, W. M., Rind, D., Romanou, A., Sato, M., Shindell, D. T., Sun, S., Syed, R. A., Tausnev, N., Tsigaridis, K., Unger, N., Voulgarakis, A., Yao, M.-S., and Zhang, J.: Configuration and assessment of the GISS ModelE2 contributions to the CMIP5 archive, J. Adv. Model. Earth Syst., 6, 141-184, https://doi.org/10.1002/2013MS000265, 2014.

Shindell, D. T.: Evaluation of the absolute regional temperature potential, Atmos. Chem. Phys., 12, 7955-7960, https://doi.org/10.5194/acp-12-7955-2012, 2012.
Shindell, D. T.: Inhomogeneous forcing and transient climate sensitivity, Nat. Clim. Chang., 4, 274-277, https://doi.org/10.1038/nclimate2136, 2014.

Shindell, D. and Faluvegi, G.: Climate response to regional radiative forcing during the twentieth century, Nat. Geosci., 2, 294-300, https://doi.org/10.1038/ngeo473, 2009.

Sillmann, J., Kharin, V. V., Zhang, X., Zwiers, F. W., and Bronaugh, D.: Climate extremes indices in the CMIP5 multimodel ensemble: Part 1. Model evaluation in the present climate, J. Geophys. Res.-Atmos., 118, 1716-1733, https://doi.org/10.1002/jgrd.50203, 2013.

Smith, C. J., Kramer, R. J., Myhre, G., Forster, P. M., Soden, B. J., Andrews, T., Boucher, O., Faluvegi, G., Fläschner, D., Hodnebrog, Ø., Kasoar, M., Kharin, V., Kirkevåg, A., Lamarque, J.-F., Mülmenstädt, J., Olivié, D., Richardson, T., Samset, B. H., Shindell, D., Stier, P., Takemura, T., Voulgarakis, A., and Watson-Parris, D.: Understanding Rapid Adjustments to Diverse Forcing Agents, Geophys. Res. Lett., 45, 12023-12031, https://doi.org/10.1029/2018GL079826, 2018.

Smith, D. M., Screen, J. A., Deser, C., Cohen, J., Fyfe, J. C., GarcíaSerrano, J., Jung, T., Kattsov, V., Matei, D., Msadek, R., Peings, Y., Sigmond, M., Ukita, J., Yoon, J.-H., and Zhang, X.: The Polar Amplification Model Intercomparison Project (PAMIP) contribution to CMIP6: investigating the causes and consequences of polar amplification, Geosci. Model Dev., 12, 1139-1164, https://doi.org/10.5194/gmd-12-1139-2019, 2019.

Stjern, C. W., Samset, B. H., Myhre, G., Forster, P. M., Hodnebrog, Ø., Andrews, T., Boucher, O., Faluvegi, G., Iversen, T., Kasoar, M., Kharin, V., Kirkevåg, A., Lamarque, J.-F., Olivieì, D., Richardson, T., Shawki, D., Shindell, D., Smith, C., Takemura, T., and Voulgarakis, A.: Rapid adjustments cause weak surface temperature response to increased black carbon concentrations, J. Geophys. Res.-Atmos., 122, 11462-11481, https://doi.org/10.1002/2017JD027326, 2017.

Stjern, C. W., Lund, M. T., Samset, B. H., Myhre, G., Forster, P. M., Andrews, T., Boucher, O., Faluvegi, G., Fläschner, D., Iversen, T., Kasoar, M., Kharin, V., Kirkevåg, A., Lamarque, J. F., Olivié, D., Richardson, T., Sand, M., Shawki, D., Shindell, D., Smith, C. J., Takemura, T., and Voulgarakis, A.: Arctic Amplification Response to Individual Climate Drivers, J. Geophys. Res.-Atmos., 124, 6698-6717, https://doi.org/10.1029/2018JD029726, 2019.

Tørseth, K., Aas, W., Breivik, K., Fjæraa, A. M., Fiebig, M., Hjellbrekke, A. G., Lund Myhre, C., Solberg, S., and Yttri, K. E.: Introduction to the European Monitoring and Evaluation Programme (EMEP) and observed atmospheric composition change during 1972-2009, Atmos. Chem. Phys., 12, 5447-5481, https://doi.org/10.5194/acp-12-5447-2012, 2012.

Twomey, S. A.: Pollution and Cloud Albedo, EOS T. Am. Geophys. Un., 58, 797-797, 1977.

Wang, H., Rasch, P. J., Easter, R. C., Singh, B., Zhang, R., Ma, P.-L., Qian, Y., Ghan, S. J., and Beagley, N.: Using an explicit emission tagging method in global modeling of source-receptor relationships for black carbon in the Arctic: Variations, sources, and transport pathways, J. Geophys. Res.-Atmos., 119, 1288812909, https://doi.org/10.1002/2014JD022297, 2014.

Westervelt, D. M.: RTP coefficients Westervelt et al ACP, figshare, Dataset, https://doi.org/10.6084/m9.figshare.10669322.v1, available at: https://figshare.com/articles/RTP_coefficients_ 
Westervelt_et_al_ACP/10669322, last access: 21 November 2019a.

Westervelt, D. M.: Global mean T by latitude band, figshare, Dataset, https://doi.org/10.6084/m9.figshare.10710722.v1, available at: https://figshare.com/articles/Global_mean_T_by_ latitude_band/10710722, last access: 21 November 2019b.

Westervelt, D. M., Horowitz, L. W., Naik, V., Golaz, J.-C., and Mauzerall, D. L.: Radiative forcing and climate response to projected 21st century aerosol decreases, Atmos. Chem. Phys., 15, 12681-12703, https://doi.org/10.5194/acp-15-12681-2015, 2015.

Westervelt, D. M., Conley, A. J., Fiore, A. M., Lamarque, J.-F., Shindell, D., Previdi, M., Faluvegi, G., Correa, G., and Horowitz, L. W.: Multimodel precipitation responses to removal of U.S. sulfur dioxide emissions, J. Geophys. Res.-Atmos., 122, 50245038, https://doi.org/10.1002/2017JD026756, 2017.

Westervelt, D. M., Conley, A. J., Fiore, A. M., Lamarque, J.-F., Shindell, D. T., Previdi, M., Mascioli, N. R., Faluvegi, G., Correa, G., and Horowitz, L. W.: Connecting regional aerosol emissions reductions to local and remote precipitation responses, Atmos. Chem. Phys., 18, 12461-12475, https://doi.org/10.5194/acp-18-12461-2018, 2018.
Wilks, D. S. and Wilks, D. S.: "The Stippling Shows Statistically Significant Grid Points": How Research Results are Routinely Overstated and Overinterpreted, and What to Do about It, B. Am. Meteorol. Soc., 97, 2263-2273, https://doi.org/10.1175/BAMSD-15-00267.1, 2016.

Zhao, A., Bollasina, M. A., and Stevenson, D. S.: Strong Influence of Aerosol Reductions on Future Heatwaves, Geophys. Res. Lett., 46, 4913-4923, https://doi.org/10.1029/2019GL082269, 2019.

Zwiers, F. W. and von Storch, H.: Taking Serial Correlation into Account in Tests of the Mean, J Climate, $\quad 8, \quad 336-351, \quad$ https://doi.org/10.1175/15200442(1995)008<0336:TSCIAI>2.0.CO;2, 1995. 